Prepared in cooperation with the Legislative-Citizen Commission on Minnesota Resources and St. Croix Watershed Research Station-Science Museum of Minnesota

\title{
Updates to the Madison Lake (Minnesota) CE-QUAL-W2 Water-Quality Model for Assessing Algal Community Dynamics
}

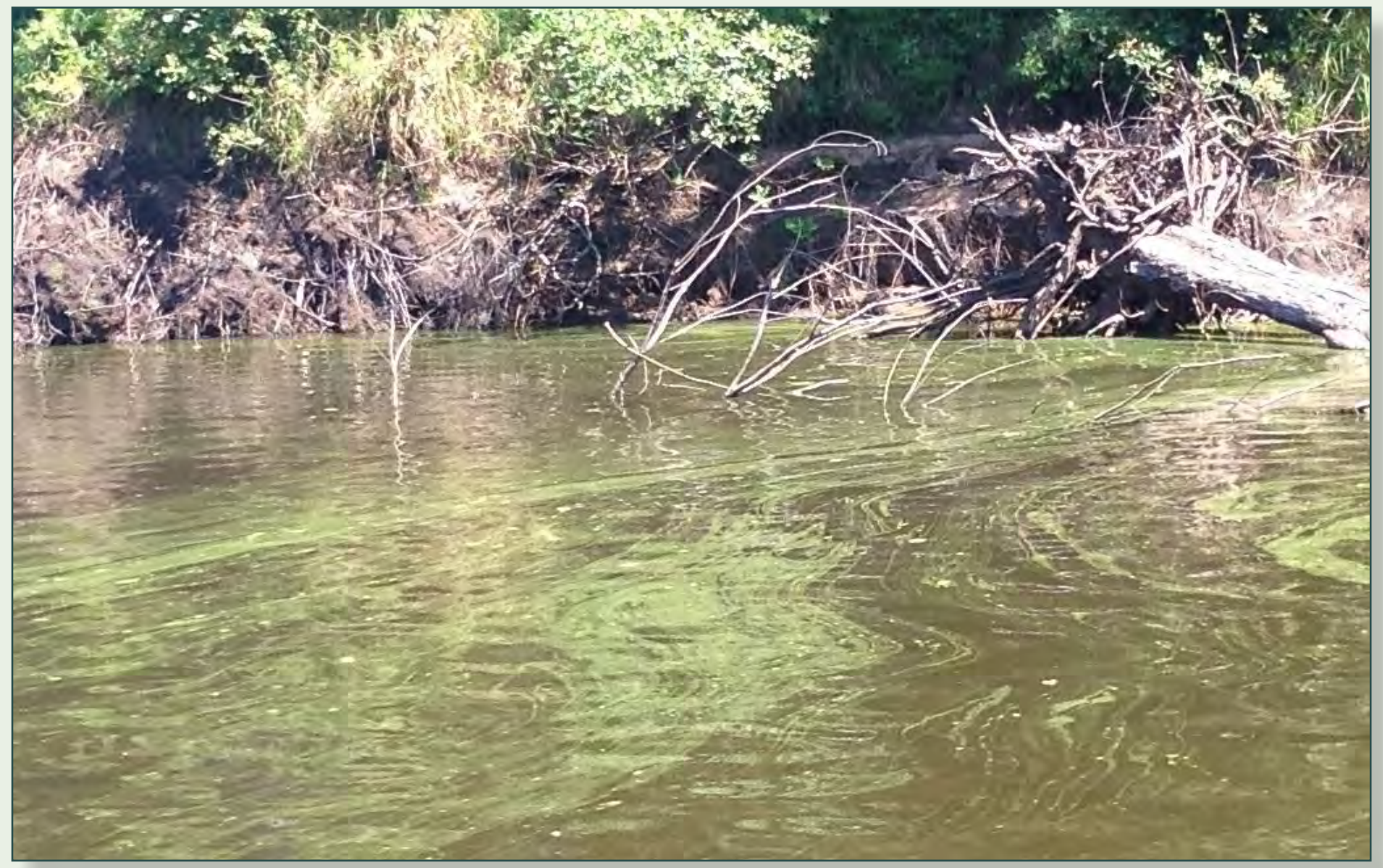

Scientific Investigations Report 2019-5124 
Cover. Photograph showing midsummer algal bloom, Lake St. Croix near Afton, Minnesota. Photograph taken August 2012 by Richard Kiesling, U.S. Geological Survey.

Back cover. Photograph showing Pearl Lake, with submerged aquatic in the foreground, looking across Pearl Lake, Minnesota. Photograph taken July 2015 by Les Warren, St. Cloud State University, used with permission. 


\section{Updates to the Madison Lake (Minnesota) CE-QUAL-W2 Water-Quality Model for Assessing Algal Community Dynamics}

By Erik A. Smith and Richard L. Kiesling

Prepared in cooperation with the Legislative-Citizen Commission on Minnesota

Resources and St. Croix Watershed Research Station-Science Museum of Minnesota

Scientific Investigations Report 2019-5124 


\title{
U.S. Department of the Interior DAVID BERNHARDT, Secretary
}

\author{
U.S. Geological Survey \\ James F. Reilly II, Director
}

\section{U.S. Geological Survey, Reston, Virginia: 2019}

For more information on the USGS - the Federal source for science about the Earth, its natural and living resources, natural hazards, and the environment-visit https://www.usgs.gov or call 1-888-ASK-USGS.

For an overview of USGS information products, including maps, imagery, and publications, visit https://store.usgs.gov.

Any use of trade, firm, or product names is for descriptive purposes only and does not imply endorsement by the U.S. Government.

Although this information product, for the most part, is in the public domain, it also may contain copyrighted materials as noted in the text. Permission to reproduce copyrighted items must be secured from the copyright owner.

Suggested citation:

Smith, E.A., and Kiesling, R.L., 2019, Updates to the Madison Lake (Minnesota) CE-QUAL-W2 water-quality model for assessing algal community dynamics: U.S. Geological Survey Scientific Investigations Report 2019-5124, 35 p., https://doi.org/10.3133/sir20195124.

Associated data for this publication:

Smith, E.A., 2019, Updated CE-QUAL-W2 water-quality model for Madison Lake, Minnesota, 2014 and 2016:

U.S. Geological Survey data release, https://doi.org/10.5066/P92YEVPO.

ISSN 2331-1258 (online) 


\section{Acknowledgments}

Funding for this study was provided by a grant from the Environmental and Natural Resource Trust Fund of Minnesota (Legislative-Citizen Commission on Minnesota Resources) to the St. Croix Watershed Research Station-Science Museum of Minnesota. This report presents a compilation of information supplied by several agencies and individuals, mainly the Minnesota Department of Natural Resources and Minnesota Pollution Control Agency.

Annett Sullivan and Jeffrey Ziegeweid of the U.S. Geological Survey are greatly acknowledged for technical reviews of the report. 



\section{Contents}

Acknowledgments ……...................................................................................................................

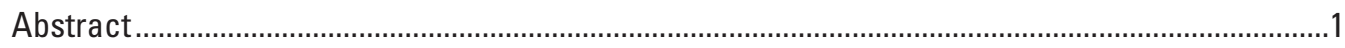

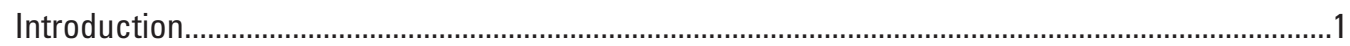

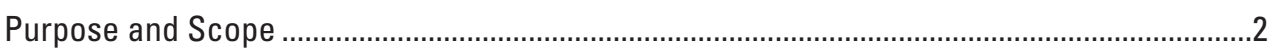

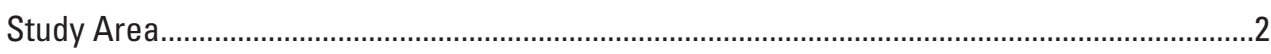

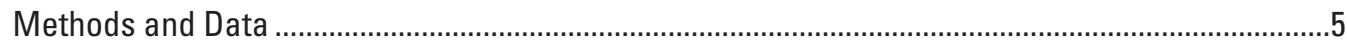

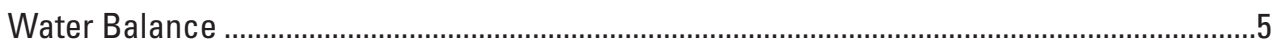

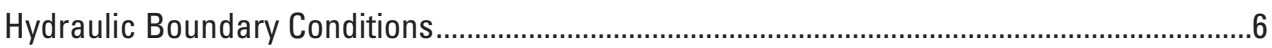

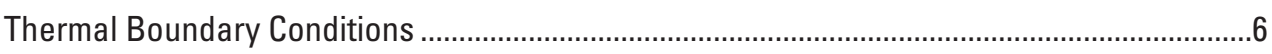

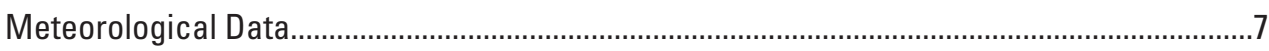

Water Quality, Data Collection, Vertical Profiles, and Laboratory Analyses ..............................7

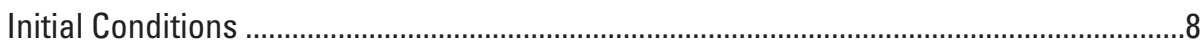

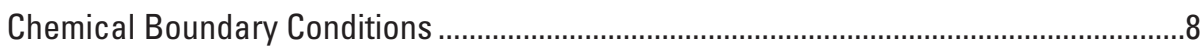

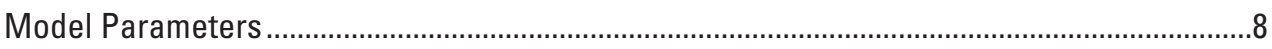

Model Calibration and Validation .............................................................................................

Water Balance ……….........................................................................................................

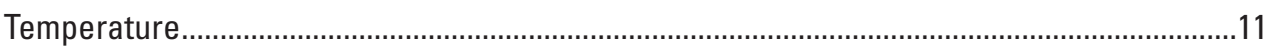

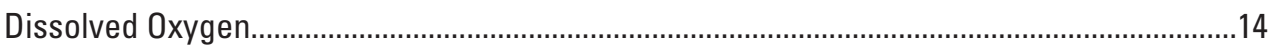

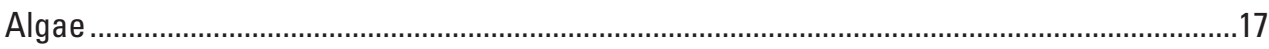

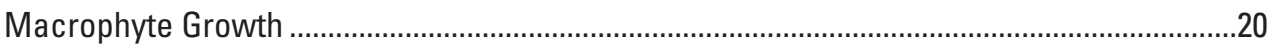

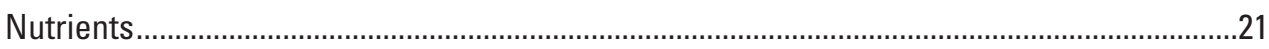

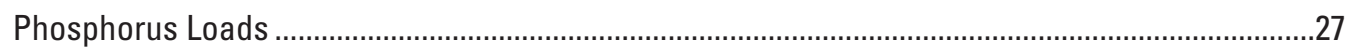

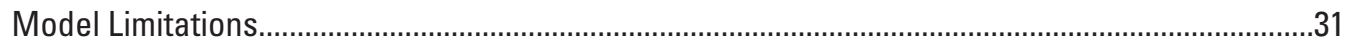

Summary

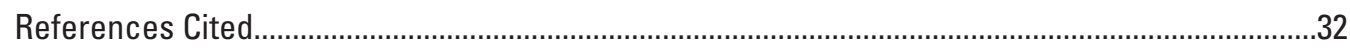

\section{Figures}

1. Map showing location of water-quality sampling sites and model segmentation for Madison Lake, Minnesota ...................................................................................................

2. Graphs showing simulated and measured water temperature for vertical profiles at Madison Lake southwest deep point near Madison Lake, Minnesota, for eight dates in 2014

3. Graphs showing simulated and measured water temperature for vertical profiles at Madison Lake southwest deep point near Madison Lake, Minnesota, for nine dates in 2016

4. Graphs showing simulated and measured dissolved oxygen concentration vertical profiles at Madison Lake southwest deep point near Madison Lake, Minnesota, for eight dates in 2014

\section{3}

Graphs showing simulated and measured dissolved oxygen concentration vertical profiles at Madison Lake southwest deep point near Madison Lake, Minnesota, for nine dates in 2016 . 
6. Graph showing simulated and measured algal group distributions for the 1-meter depth at Madison Lake southwest deep point near Madison Lake, Minnesota, May 15 to November 1, 2014

7. Graph showing simulated and measured chlorophyll a concentrations for the 1-meter depth at Madison Lake southwest deep point near Madison Lake, Minnesota (segment 7), May 15 to November 1, 2014.

8. Graph showing simulated and measured algal group distributions for the 1-meter depth at Madison Lake southwest deep point near Madison Lake, Minnesota, March 30 to November 23, 2016

9. Graph showing simulated and measured chlorophyll a concentrations for the 1-meter depth at Madison Lake southwest deep point near Madison Lake, Minnesota (segment 7), March 30 to November 23, 2016.

10. Graph showing simulated and measured dissolved ammonia concentrations at 1 meter below the water surface in model segment 7 containing the Madison Lake southwest deep point near Madison Lake, Minnesota, May 15 to November 1, 2014 .

11. Graph showing simulated and measured dissolved ammonia concentrations at 1 meter below the water surface in model segment 7 containing the Madison Lake southwest deep point near Madison Lake, Minnesota, March 30 to November 23, 2016

12. Graph showing simulated and measured dissolved nitrate plus nitrite concentrations at 1 meter below the water surface in model segment 7 containing the Madison Lake southwest deep point near Madison Lake, Minnesota, May 15 to November 1, 2014.

13. Graph showing simulated and measured dissolved nitrate plus nitrite concentrations at 1 meter below the water surface in model segment 7 containing the Madison Lake southwest deep point near Madison Lake, Minnesota, March 30 to November 23, 2016

14. Graph showing simulated and measured dissolved orthophosphate concentrations at 1 meter below the water surface in model segment 7 containing the Madison Lake southwest deep point near Madison Lake, Minnesota, May 15 to November 1, 2014

15. Graph showing simulated and measured dissolved orthophosphate concentrations at 1 meter below the water surface in model segment 7 containing the Madison Lake southwest deep point near Madison Lake, Minnesota, March 30 to November 23, 2016.

16. Graph showing simulated and measured total Kjeldahl nitrogen concentrations at 1 meter below the water surface in model segment 7 containing the Madison Lake southwest deep point near Madison Lake...

17. Graph showing simulated and measured total Kjeldahl nitrogen concentrations at 1 meter below the water surface in model segment 7 containing the Madison Lake southwest deep point near Madison Lake, Minnesota, March 30 to November 23, 2016

18. Graph showing simulated and measured total phosphorus concentrations at 1 meter and 16.5 meters below the water surface in model segment 7 containing the Madison Lake southwest deep point near Madison Lake, Minnesota, May 15 to November 1, 2014

19. Graph showing simulated and measured total phosphorus concentrations at 1 meter and 15.5 meters below the water surface in model segment 7 containing the Madison Lake southwest deep point near Madison Lake, Minnesota, March 30 to November 23, 2016 
20. Graph showing total monthly phosphorus loads, in kilograms per month, for the 2014 and 2016 model years for the updated model.

\section{Tables}

1. Location of continuous pressure transducers, water-quality sondes, thermistors, and discrete water-quality measurements used for the development of model input or calibration/validation of water temperature, dissolved oxygen, and water-quality constituents

2. Water-quality methods for constituents analyzed in water samples from Madison Lake, 2014 and 2016.

3. Relative counts and converted algal biomass for Madison Lake southwest deep point near Madison Lake, Minnesota, 2014 and 2016

4. Initial constituent concentrations for the Madison Lake CE-QUAL-W2 model: 2014 calibration and 2016 validation runs.

5. Summary of mean absolute error and root mean square error values for calibration (2014) and validation (2016) runs for Madison Lake at Madison Lake southwest deep point near Madison Lake, Minnesota.

6. Summary of phosphorus loading for updated Madison Lake model $(2014,2016)$, original Madison Lake model, and two phosphorus loading scenarios, according to load estimates and internal CE-QUAL-W2 calculations..

\section{Conversion Factors}

International System of Units to U.S. customary units

\begin{tabular}{lcl}
\hline \multicolumn{1}{c}{ Multiply } & By & \multicolumn{1}{c}{ To obtain } \\
\hline meter $(\mathrm{m})$ & Length & foot (ft) \\
meter $(\mathrm{m})$ & 3.281 & inches (in.) \\
kilometer $(\mathrm{km})$ & 39.37 & mile (mi) \\
\hline & 0.6215 & \\
\hline meter per year $(\mathrm{m} / \mathrm{yr})$ & Flow rate & foot per year $(\mathrm{ft} / \mathrm{yr})$ \\
\hline & 3.281 & British thermal unit per hour per \\
\hline watt per square meter $\left(\mathrm{W} / \mathrm{m}^{2}\right)$ & Energy & square foot $\left(\mathrm{Btu} / \mathrm{hr} / \mathrm{ft}^{2}\right)$ \\
\hline
\end{tabular}

Temperature in degrees Celsius $\left({ }^{\circ} \mathrm{C}\right)$ may be converted to degrees Fahrenheit $\left({ }^{\circ} \mathrm{F}\right)$ as

$$
{ }^{\circ} \mathrm{F}=\left(1.8 \times{ }^{\circ} \mathrm{C}\right)+32 .
$$

Vertical coordinate information is referenced to the North American Vertical Datum of 1988 (NAVD 88), unless otherwise indicated.

Horizontal coordinate information is referenced to the North American Datum of 1983 (NAD 83).

Elevation, as used in this report, refers to distance above the vertical datum. 


\section{Supplemental Information}

Concentrations of chemical constituents in water are given in either milligrams per liter (mg/L) or micrograms per liter $(\mu \mathrm{g} / \mathrm{L})$.

\section{Abbreviations}

$\begin{array}{ll}< & \text { less than } \\ \text { DHEL } & \text { Department of Health Environmental Laboratory } \\ \text { DO } & \text { dissolved oxygen } \\ \text { MAE } & \text { mean absolute error } \\ \text { MNDNR } & \text { Minnesota Department of Natural Resources } \\ R^{2} & \text { coefficient of determination } \\ \text { RMSE } & \text { root mean square error } \\ \text { USGS } & \text { U.S. Geological Survey }\end{array}$




\title{
Updates to the Madison Lake (Minnesota) CE-QUAL-W2 Water-Quality Model for Assessing Algal Community Dynamics
}

\author{
By Erik A. Smith and Richard L. Kiesling
}

\section{Abstract}

A previously developed CE-QUAL-W2 model for Madison Lake, Minnesota, simulated the algal community dynamics, water quality, and fish habitat suitability of Madison Lake under recent (2014) meteorological conditions. Additionally, this previously developed model simulated the complex interplay between external nutrient loading, internal nutrient loading from sediment release of phosphorus, and the organic matter decomposition of the algal biomass. However, the partitioning of Cyanophyta within the modeling framework was simplified to one group and did not account for how different Cyanophyta populations are affected by light conditions, use of nitrogen, temperature growth ranges, and differences in settling rates. Properly capturing Cyanophyta dynamics is important given the potential risks posed by potential large algal blooms. For example, when Cyanophyta form large blooms, recreational activities can become restricted in certain areas because of thick algal scums or algal mats, in addition to the possible production of a class of toxins, known as cyanotoxins, capable of threatening human health, domestic animals, and wildlife. Therefore, we updated the model to partition the Cyanophyta into a group that fixed nitrogen and a second, more buoyant Cyanophyta group that did not independently fix nitrogen.

The U.S. Geological Survey, in cooperation with the St. Croix Watershed Research Station (Science Museum of Minnesota) with support from the Environmental and Natural Resources Trust Fund of Minnesota (Legislative-Citizen Commission on Minnesota Resources), updated the Madison Lake CE-QUAL-W2 model to address the shortcomings of simulating Cyanophyta in the previously developed model and better characterize Cyanophyta into two groups. In addition to updating the Cyanophyta group differentiation, the part of the model that handles the simulation of algal community dynamics was updated while preserving model predictive capabilities for nutrients, water temperature, and dissolved oxygen. The calibration and validation of the model was done under recent meteorological conditions with large and persistent Cyanophyta blooms (2014 and 2016).
Overall, the model simulations predicted the persistently large total phosphorus concentrations in the hypolimnion of Madison Lake and key differences in nutrient concentrations between 2014 and 2016. The Cyanophyta bloom persistence throughout the summer was also simulated by the model in 2014 and 2016, a critical goal of the model update. Finally, monthly total phosphorus budgets were calculated for the updated Madison Lake model for 2014 and 2016.

\section{Introduction}

Across the spectrum of freshwater lakes worldwide, high anthropogenic nitrogen and phosphorus inputs into freshwater lakes have been implicated as one of the primary causes of the alarming rise in Cyanophyta blooms (also known as cyanobacteria or blue-green algae) over the past several decades (Xu and others, 2010; Paerl and Otten, 2013). These blooms can reduce the recreational and ecological value of lakes, including lakes across Minnesota. For Madison Lake (fig. 1), a fairly large and deep lake in southern Minnesota, Cyanophyta have become an increasingly dominant component of the algal community. Cyanophyta blooms create potential concerns for residents of Madison Lake because many Cyanophyta species can produce potent toxins and can lead to harmful algal blooms. When Cyanophyta form a toxic harmful algal bloom, potential impairments include restricted recreational activities because of algal scums or algal mats and the production of toxins (for example, microcystin) in amounts capable of threatening human health, domestic animals, and wildlife (O'Neil and others, 2012; Graham and others, 2016). Exposure to environmental concentrations of cyanotoxins can cause hepatic, neurologic, respiratory, and dermatologic problems in humans (Merel and others, 2013; Loftin and others, 2016).

Although Cyanophyta have been common components of the Madison Lake phytoplankton community for some time, recent Madison Lake data have indicated a proliferation of Cyanophyta (Lindon and Heiskary, 2007, 2009). From 2013 through 2018, routine field monitoring samples indicated 
Cyanophyta was a fairly large percentage of the algal community, by the overall number of individuals (counts) and the overall biovolume (Casey Schoenebeck, written commun., 2018). Also, it was determined that several Cyanophyta genera persisted throughout much of the summer and into the fall months (July through October).

The Minnesota Department of Natural Resources (MNDNR) and other local resource managers are concerned that Cyanophyta blooms could negatively affect Madison Lake. Madison Lake is a popular recreational lake for fishing, swimming, and boating and also has a dense community of year-round residents (Lindon and others, 2010). Persistent algal blooms, whether the blooms are Cyanophyta or other types of algae, can negatively affect the fishery indirectly by decreasing dissolved oxygen (DO). Madison Lake contains high-quality populations of fish species (Minnesota Department of Natural Resources, 2016a) such as northern pike (Esox lucius), smallmouth bass (Micropterus dolomieu), and bluegill (Lepomis macrochirus). Continuous monitoring of epilimnetic and hypolimnetic DO in Madison Lake has documented prolonged periods of hypoxia, associated with periods of long water residence time and sustained high levels of algal biomass that last for weeks. When blooms enter stationary phase growth or start to senesce, bacteria mineralize the sinking algal biomass, consuming large amounts of oxygen and thereby decreasing DO concentrations. Large blooms can result in hypoxic areas, which, in turn, can endanger the fishery by creating habitat bottlenecks; therefore, large algal blooms can negatively affect the overall health of Madison Lake in multiple ways.

Previous summaries of Madison Lake water quality have documented large inputs of nitrogen and phosphorus into Madison Lake (Lindon and others, 2010; Smith and others, 2017). A previously developed CE-QUAL-W2 model for Madison Lake was used to demonstrate that internal loading from sediments during hypoxic or anoxic conditions contributed a substantial part of the total phosphorus load into Madison Lake (Smith and others, 2017). This model partitioned the algal community into four groups, including a general group for Cyanophyta (termed blue-green algae in the earlier report); however, this previously developed model did not account for how different Cyanophyta populations are affected by light conditions, use of nitrogen, temperature growth ranges, and differences in settling rates. An update to the model was needed to provide a more sophisticated simulation of algal community dynamics to address concerns about increased proliferation of Cyanophyta blooms.

The U.S. Geological Survey (USGS), in cooperation with the St. Croix Watershed Research Station (Science Museum of Minnesota) with support from the Environmental and Natural Resources Trust Fund of Minnesota (Legislative-Citizen Commission on Minnesota Resources), updated the Madison Lake CE-QUAL-W2 model to address the shortcomings of simulating Cyanophyta in the previously developed model (Smith and others, 2017). In addition to further differentiating Cyanophyta groups, the part of the model that handles the simulation of algal community dynamics was updated while preserving model predictive capabilities for nutrients, water temperature, and DO. The calibration and validation of the updated model were done under recent meteorological conditions with large and persistent Cyanophyta blooms (2014 and 2016). With the updated model, further scenarios that can provide external nutrient loading information for different management scenarios or past environmental conditions can be run.

\section{Purpose and Scope}

The purpose of this report is to document updates to a previously developed CE-QUAL-W2 hydrodynamic and water-quality model of Madison Lake, Minnesota (Smith and others, 2017). The previous version simulated phytoplankton into four general algal communities or groups: (1) Bacillariophyta (diatoms) and Chrysophyta (chrysophytes); (2) Chlorophyta (green algae); (3) Cyanophyta (blue-green algae); and, (4) Haptophyta and Cryptophyta (flagellates). For the updated model, the blue-green algae group, referred to as Cyanophyta in this report, has been divided into two groups: a nitrogen-fixing Cyanophyta group, generally representative of Anabaena, Dolichospermum, and Cylindrospermopsis, and a nonfixing, buoyant Cyanophyta group, generally representative of Planktothrix, Microcystis, and Woronichinia.

\section{Study Area}

Madison Lake (fig. 1) in Blue Earth County, Minn., is in the Le Sueur River Basin, part of the greater Minnesota River Basin (not shown; Lindon and others, 2010). Madison Lake is weakly dimictic, generally starting off as well mixed before early summer, and has a weak thermocline that develops in the summer months; the lake mixes again in the late fall (Lindon and others, 2010). DO is well mixed in the early spring (April to May) and late fall (mid-October), with a substantial part of the hypolimnion becoming anoxic by midsummer; however, anoxia can develop earlier in some years and subsist late into the fall, especially when the thermocline develops early (Lindon and others, 2010). The water balance of the drainage basin for Madison Lake is typically controlled by a spring snowmelt in late March or early April, followed by periodic large rain events in the summer. The mean precipitation in the region for 1981-2010 is 0.82 meter per year (National Centers for Environmental Information, 2016).

Primary inflows to Madison Lake are in the northeast and southeast parts of the lake, and both inflows were primary sampling locations for nutrient and major inorganic constituents, water temperature, and streamflow (table 1). The tributary to Madison Lake, northeast corner, near Madison Lake, Minn. (USGS station 05320130 [U.S. Geological Survey, 2019]; hereafter referred to as the "northeast inlet"), flows into the larger and shallow northeast bay of Madison Lake. The tributary to Madison Lake, southeast corner, near 


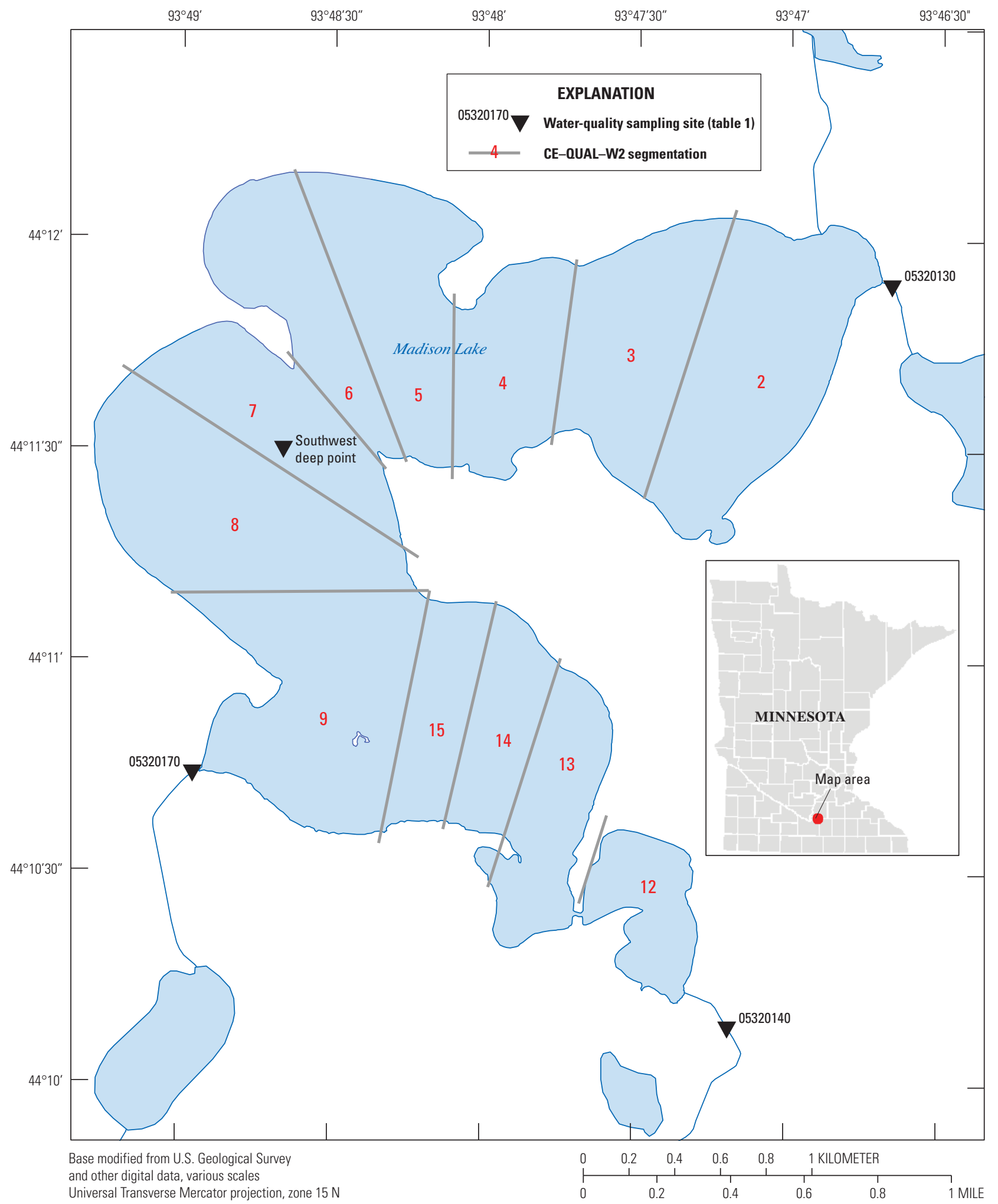

North American Datum of 1983

Figure 1. Location of water-quality sampling sites and model segmentation for Madison Lake, Minnesota. 


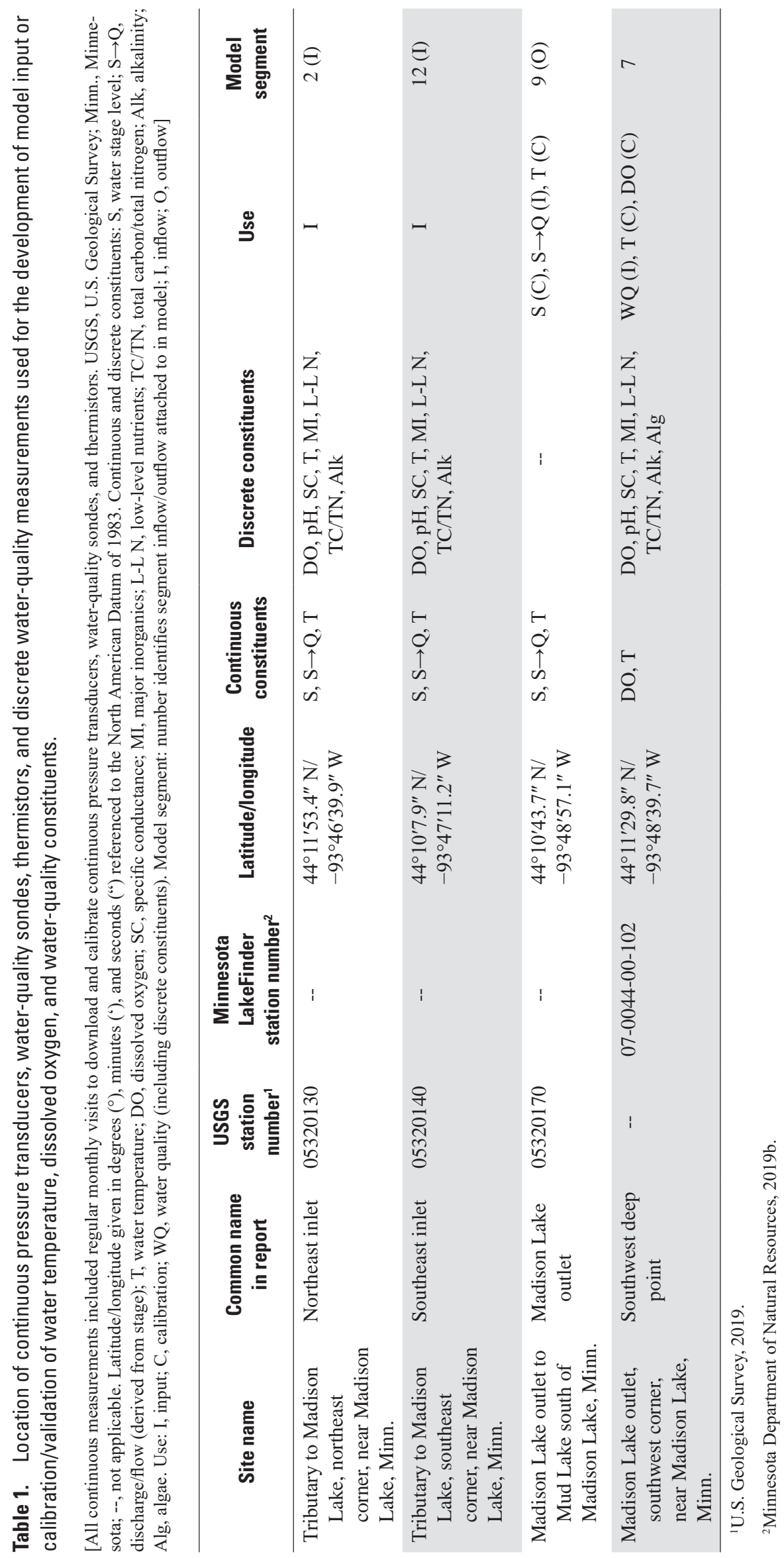


Madison Lake, Minn. (USGS station 05320140; hereafter referred to as the "southeast inlet"), flows into the shallow part of the smallest bay (by area) along the southeast shoreline. The primary outflow for Madison Lake is the site Madison Lake outlet, southwest corner, near Madison Lake, Minn. (USGS station 05320170 [U.S. Geological Survey, 2019]; hereafter referred to as the "Madison Lake outlet"), along the southwest part of the lake. The deep area in the southwest bay, also the largest deep area by areal extent, was sampled at the site Madison Lake southwest deep point near Madison Lake, Minn. (Minnesota LakeFinder Station 07-0044-00-102; hereafter referred to as "southwest deep point"), and has a depth of about 18 meters ( $\mathrm{m}$; table 1$)$. This location was used for extensive inlake water-quality sampling, periodic vertical profiles of water temperature and DO, and continuous monitoring of water temperature at various depths (Minnesota Pollution Control Agency, 2018).

\section{Methods and Data}

The Madison Lake CE-QUAL-W2 model was previously developed for 2014 to simulate algal community dynamics, water-surface elevations, flow, water quality, and fish habitat suitability (Smith and others, 2017). For the current study described in this report, the previously developed (original) model was updated to redistribute the algal community into five distinct algal groups or divisions rather than four groups. The updated model was recalibrated for 2014 and validated for 2016. The previous and updated versions for Madison Lake were developed with CE-QUAL-W2 (version 4.0, available at http://www.ce.pdx.edu/w2/), a two-dimensional, laterally averaged, hydrodynamic and water-quality model originally developed by the U.S. Army Corps of Engineers (Cole and Wells, 2015). The CE-QUAL-W2 model calculates the hydrodynamic properties of water-surface elevation, velocity, and temperature and can simulate water-quality variables in addition to temperature. An advantage of the CE-QUAL-W2 model is that the hydrodynamic and water-quality modules are coupled together through an equation of state for density, dependent on temperature, suspended solids, and dissolved solids. The CE-QUAL-W2 model also enables the water-quality module to feed back into the hydrodynamic module; however, because of this coupling, changes to the model specifications for algal growth and senescence can affect the other parts of the model; therefore, the changes to the algal dynamics and some other updates required a reassessment of the model fit.

The CE-QUAL-W2 computational grid, based on available bathymetric data (Minnesota Department of Natural Resources, 2016b) and a digital elevation model (U.S. Geological Survey, 2016), was left unaltered and is described in detail in Smith and others (2017). In summary, the CE-QUAL-W2 grid was separated into segments that laterally average across the lake, with individual segments grouped together into branches. Each branch is grouped together to represent the computational grid of the water body. For Madison Lake, the CE-QUAL-W2 water body (fig. 1) was grouped together from two separate branches: (1) branch 1 starts at segment 2 and continues through segment 9; (2) branch 2 separates out the southeast part of Madison Lake, where the southeast inlet flows into the lake, and connects to branch 1 at segment 9 via segment 15.

This study followed a similar calibration strategy as other CE-QUAL-W2 modeling studies completed by the USGS in Minnesota (Smith and others, 2014, 2017, 2018). Calibration targets included a water balance calibration based on watersurface elevation, chlorophyll $a$, algae, and nutrients (ammonia, nitrate plus nitrite, total Kjeldahl nitrogen, total phosphorus, orthophosphate). Vertical variations in temperature and DO are important for distinguishing temporal variations in the lake epilimnion, hypolimnion, and mixed layers; therefore, emphasis was placed on the synoptic depth profiles of temperature and DO from the southwest deep point.

The CE-QUAL-W2 model required time series inputs of hydrological, thermal, water quality, and meteorological data. A summary of the discrete and continuous data collected for Madison Lake, further split by sampling locations, is shown in table 1. All the input data used for calendar year 2014 were documented in Smith and others (2017). The same basic data and sources were used for 2016, but continuous streamflow and temperature were unavailable for 2016, so a surrogate dataset was developed to estimate streamflow and temperature. This surrogate dataset is described further in the "Hydraulic Boundary Conditions" and "Thermal Boundary Conditions" sections.

The full model archive for the updated model described in this report consists of the source code, geospatial information, calibration information, and all model inputs and outputs generated during this study. The model archive is available via a USGS data release (Smith, 2019; https://doi.org/10.5066/ P92YEVPO).

\section{Water Balance}

The water balance of Madison Lake for May 15-November 1, 2014, was left unaltered (Smith and others, 2017), but a new water balance was required for March 30-November 23, 2016. Similar to the 2014 water balance, the 2016 water balance was completed by comparing measured water levels to simulated water levels; however, unlike 2014, continuous water levels were unavailable for the Madison Lake outlet. Therefore, for 2016, simulated water levels were compared to the daily water-surface elevations collected by the Lake Level Minnesota Monitoring Program (Minnesota Department of Natural Resources, 2019a). Daily water-surface elevations are available from the MNDNR Lake Finder website (Minnesota Department of Natural Resources, 2019b). 


\section{Hydraulic Boundary Conditions}

Lake inflows used in the CE-QUAL-W2 model were obtained from two separate channels that flow into Madison Lake. The northeast inlet streamflow (fig. 1; table 1) was measured in the channel connecting several small lakes and wetlands to Madison Lake. The southeast inlet streamflow (fig. 1; table 1) was measured in the channel connecting Schoolhouse and Goolsby Lake to Madison Lake (not shown). Submersible pressure transducers were installed for the northeast inlet, southeast inlet, and Madison Lake outflow from May to November 2014. These transducers collected continuous water-surface level (stage or gage height) measurements every 15 minutes. Three corresponding measurements of streamflow and water-surface level measurements were made at each inflow site in 2014 (U.S. Geological Survey, 2019) by the MNDNR to construct the elevation-streamflow rating tables presented in appendix table 1-1 of Smith and others (2017). The elevation-streamflow rating curves were developed using graphical plotting methods similar to those described in Rantz and others (1982a, b), with linear extrapolations added to the upper and lower end of the rating curves to estimate streamflows outside of the range of measured streamflows. The Madison Lake outflow, along the southwest part of the lake, was also estimated though an elevation-streamflow rating curve, based upon four direct measurements made in 2014.

For 2016, continuous water level measurements were not available for either of the two inflow sites or the lake outflow; however, the model requires streamflow input into the model, ideally subdaily measurements. Without such a record available, the 2014 elevation-streamflow rating table was applied to the daily water-surface elevations from the Lake Level Minnesota Monitoring Program (Minnesota Department of Natural Resources, 2019a, b). Daily inflows and outflow were calculated using this methodology and input into the model. The daily water-surface elevations used for 2016, available from the Lake Finder website, are also available as part of the full CE-QUAL-W2 model archive in the el_obs.csv file (in meters) contained in the MadisonLake 2016.zip file in the model archive available via USGS data release (Smith, 2019).

For 2014 and 2016, additional water inflows to Madison Lake were assumed from ungaged locations in the lake and from groundwater flow, referred to as distributed tributary flow. Distributed tributary flow was input into the model in daily time steps and distributed evenly across all the model segments. To account for this additional flow, water was iteratively added to the distributed tributary flow through successive model runs until a satisfactory match was attained between simulated and measured water-surface elevations. Surrogate records for 2016 inlet and distributed tributary inflows are included in the model archive available via USGS data release (Smith, 2019).

\section{Thermal Boundary Conditions}

Inflowing water temperature was collected at the northeast inlet and the southeast inlet concurrently with water elevations in 2014 using submersible pressure transducers. The temperatures were then converted to the appropriate data format for CE-QUAL-W2 and applied as tin_br1, the inflowing water temperature via the northeast inlet into branch 1 , and tin_br2, the inflowing water temperature via the southeast inlet into branch 2 (Smith and others, 2017; Smith, 2019). Distributed tributary flow also had associated temperature records within the model framework, applied as tdt_br1 and tdt_br2 for the two separate branches. A continuous water temperature record from a nearby observation well with a depth of $3.8 \mathrm{~m}$ (Minnesota Unique Identification Number 792526) was assumed as the distributed tributary flow temperature (Andrew Streitz, unpub. data, 2018). Conversions were not applied to this temperature record, and the temperature record is available as part of the CE-QUAL-W2 model archive (Smith, 2019). The 2014 and 2016 daily mean temperatures for the northeast inlet (USGS station 05320130) and for the southeast inlet (USGS station 05320140) are available as tin_br1.csv and tin_br2.csv, respectively, with the CE-QUAL-W2 model archive (Smith, 2019).

Measured water temperature data were not available for 2016 for either the northeast or southeast inlet. Instead, surrogate water temperature datasets were constructed using a simple linear regression relation between daily air temperatures from the Mankato Regional Airport and daily water temperatures from the two inlet transducers measured in 2014 (Preud'homme and Stefan, 1992). The following regression equations were then applied to daily air temperature data collected from the Mankato Regional Airport in 2016 (National Climatic Data Center, 2016, 2018):

$$
\begin{aligned}
& \text { temperature }(\text { branch } 1)=1.0208 \times \text { daily air } \\
& \text { temperature }-1.4595, R^{2}=0.87 \\
& \text { temperature }(\text { branch } 2)=0.993 \times \text { daily air } \\
& \text { temperature }+0.4015, R^{2}=0.90
\end{aligned}
$$

The coefficient of determination $\left(R^{2}\right)$ values of the regression equations were 0.87 and 0.90 for branches 1 and 2, respectively. The 2016 surrogate water temperature records are included in the model archive (Smith, 2019). 


\section{Meteorological Data}

Meteorological data are required as inputs to the CEQUAL-W2 model because surface boundary conditions are important to the surface heat exchange, solar radiation absorption, wind stress, and gas exchange components of the model. Required meteorological data include air temperature, dew point temperature, wind speed, wind direction, and cloud cover. All unit conversions from the meteorological data to the required units for the model were straightforward with the exception of cloud cover. The qualitative sky cover parameter (that is, clear, scattered, broken, and overcast) was converted to an integer value ranging from 0 to 10 : clear is 1 , scattered (1/8 to $1 / 2$ cloud coverage) is 5 , and overcast is 10 . All the required data were available at hourly intervals for the Mankato Regional Airport (U.S. Air Force station identification number 726585), which is less than $(<) 12.5$ kilometers $(\mathrm{km})$ west of Madison Lake, from the Climate Data Online portal (National Climatic Data Center, 2016, 2018). Based on the latitude and longitude of the lake and the required meteorological inputs, evapotranspiration was included in the water balance as an internal CE-QUAL-W2 calculation.

\section{Water Quality, Data Collection, Vertical Profiles, and Laboratory Analyses}

Limnological characteristics, including properties that could affect trophic state, were examined at the southwest deep point. This site was sampled by MNDNR staff 5 times in 2014 (Smith and others, 2017) and 5-11 times (depending on the constituent) in 2016. Samples were collected near the surface (between 0 and $2 \mathrm{~m}$ ) and at depth, averaging between 15.5 and 16.5 m, using a Kemmerer sampler (Wildco 1200E; Wildlife Supply Co., Yulee, Florida) and were analyzed using methods described in table 2 to determine concentrations of nutrients, chlorophyll $a$, total dissolved solids, major ions (total silica and dissolved iron), and algal counts. Water samples were filtered (through a 0.45 -micrometer filter) for dissolved analysis or not filtered for total analysis and preserved as required (U.S. Environmental Protection Agency, 1993a, b, c, d). Alkalinity was determined by incremental titration at the field location (Wilde, variously dated). Secchi-disk transparency (Wetzel, 2001) was measured at each vertical profile location to estimate photic depth. Vertical profiles (about 1-m intervals) of temperature, $\mathrm{DO}$ concentration, $\mathrm{pH}$, and specific conductance were measured by MNDNR staff with a multiparameter Hydrolab sonde at each lake site in conjunction with the water samples.

Water samples also were collected by MNDNR at the inflow sites (table 1), although no algal data were collected for the inflow sites. Methods used to collect samples and analyzed constituents at inflow sites were identical to methods and constituents for limnological sites. Water samples were collected four to five times in 2014 and five to six times in 2016, depending on constituents. Analyses of water samples collected by the MNDNR at the limnological and inflow sites were completed by the Minnesota Department of Health Environmental Laboratory (DHEL) in St. Paul, Minn., for every

Table 2. Water-quality methods for constituents analyzed in water samples from Madison Lake, 2014 and 2016.

[mg/L, milligram per liter; EPA, U.S. Environmental Protection Agency; SM, standard method; --, not analyzed; $\mathrm{SiO}_{2}$, silicon dioxide; ASA, PhycoTech proprietary data management software]

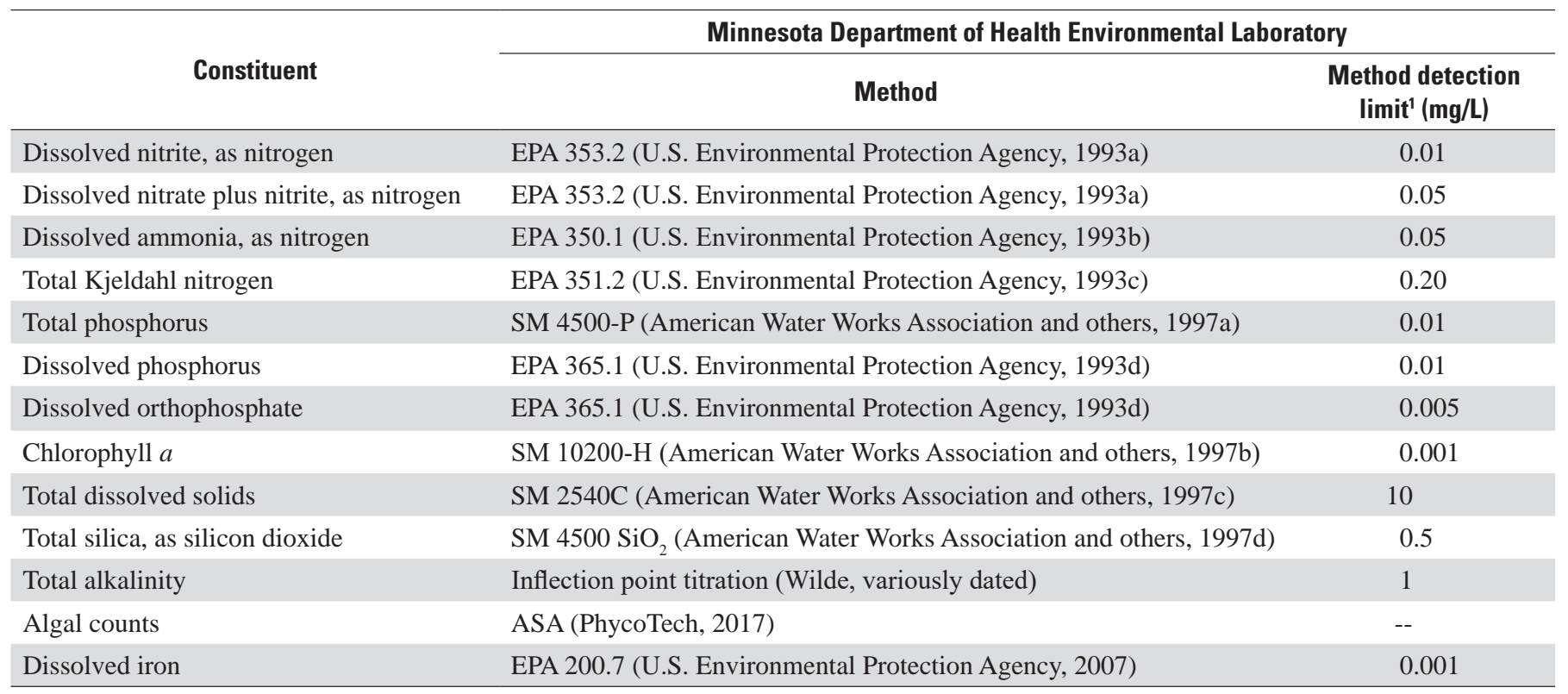

${ }^{1}$ The minimum detection limit is the minimum concentration of a substance that can be measured and reported with a 99-percent confidence that the analyte concentration is greater than 0 (U.S. Environmental Protection Agency, 2002). 
constituent but algae. All samples analyzed by the Minnesota DHEL have been previously reviewed and published and are available online (Minnesota Pollution Control Agency, 2018). Algal data were obtained using a phytoplankton enumeration technique by PhycoTech, Inc. (PhycoTech, 2019). All algal data are presented in table 3 . Raw relative count data were converted to algal biomass by assuming an algal biomass (in milligrams per liter) to chlorophyll $a$ (in micrograms per liter) ratio of 0.05 and multiplying by the chlorophyll $a$ concentration collected on the same day. This ratio is different from the ratio applied for Smith and others (2017) for 2014 data, so table 3 supersedes Smith and others (2017) unless applied with the earlier version of the model.

A primary data-quality objective was to ensure that samples were representative of the water bodies in the study area. Quality assurance was assessed with specific procedures to ensure data reliability, assess the quality of the sample data, and ensure the quality-assurance plan for this study followed MNDNR guidelines (Anderson and Martin, 2015). Additional quality assurance specific to Minnesota DHEL is available online (Minnesota Department of Health, 2016). Results from available quality-assurance data associated with water-quality data used for input to the model and for calibration and validation of the model were reviewed before the modeling efforts. Overall, the water-quality datasets (discrete samples collected at specific streamflows or lake elevations) for the calibration and validation periods were considered appropriate for the range of environmental conditions simulated for this study.

\section{Initial Conditions}

Each simulated constituent (including temperature) must have an initial, single concentration for the lake or a gridwide initial vertical profile of concentrations at the start of each model run. Initial values for water-quality constituents, water-surface elevations, and water temperatures were set to measured values at the start of simulation for 2014 and 2016. Initial constituent concentrations are presented in table 4 for the calibration (2014) and validation (2016) runs; initial constituent concentrations were considered uniform throughout the lake for every segment and layer, except in cases with a reported range of values in a vertical profile. Initial algal concentrations in the updated CE-QUAL-W2 model (table 2) are different from the initial algal concentrations used in the original model (Smith and others, 2017).

\section{Chemical Boundary Conditions}

Each simulated water-quality constituent, including total dissolved solids, nutrients, silica, iron, organic matter, and inorganic carbon, must have a daily concentration value for all inflow tributaries (including distributed tributary flow). Because of the low frequency of discrete water-quality samples, either a daily mean concentration value was linearly interpolated between the discrete samples for each inflow tributary or a single concentration was applied for the model run for each inflow tributary. The distributed tributary inflow constituents were based on the mean concentrations for the northeast inlet site for branch 1 and the southeast inlet for branch 2. Daily concentration values are included in the model archive (Smith, 2019).

Organic matter concentrations were back calculated from the total Kjeldahl nitrogen concentration minus the dissolved ammonia concentration, with an additional calculation based on a linear relation between streamflow and the particulate organic nitrogen to total organic nitrogen ratio (Smith and others, 2014). Organic matter concentrations were further divided into four separate pools, as required by CE-QUAL-W2 (Cole and Wells, 2015): (1) labile dissolved, (2) refractory dissolved, (3) labile particulate, and (4) refractory particulate, with dissolved and particulate pools separated into labile and refractory at 30 and 70 percent, respectively.

\section{Model Parameters}

Numerous CE-QUAL-W2 models have indicated that the default hydraulic parameters are robust across different hydrologic settings (Cole and Wells, 2015). Most of the default hydraulic parameters that control the hydrodynamics and heat exchange are provided within CE-QUAL-W2 or the CE-QUAL-W2 manual (Cole and Wells, 2015). The density control for all inflows in the model allowed for the water inflows to match up with the layers within the lake that corresponded to the inflow density.

For the water-quality algorithms, more than 200 parameters control the constituent kinetics. An advantage of CEQUAL-W2 is the modular design that allows for control of the water-quality constituents by adding specific subroutines. Many of these parameters were optional depending on the inclusion of groups such as epiphyton, zooplankton, macrophytes, and algae. All hydraulic and heat exchange parameters that control the hydrodynamics were time and space invariant. Some parameters, such as the extinction coefficient of water, can be varied, but data collected in this study were insufficient to justify dynamic control of any parameters. All the parameterization for the updated Madison Lake CE-QUAL-W2 is available through the CE-QUAL-W2 control file, available in the model archive (Smith, 2019). Many of the parameters were left as the default values, whereas the remaining parameters were adjusted during the calibration process. Guidance for adjusting selected parameters also came from other USGS CE-QUAL-W2 model applications (Bales and Robbins, 1999; Flowers and others, 2001; Green and others, 2003; Sullivan and Rounds, 2004; Galloway and Green, 2006; Galloway and others, 2008; Sullivan and others, 2011; Smith and others, 2014; Cole and Wells, 2015). 
Table 3. Relative counts and converted algal biomass (in milligrams per liter) for Madison Lake southwest deep point near Madison Lake, Minnesota, 2014 and 2016.

[Dates are listed in year-month-day format. mg/L, milligram per liter]

\begin{tabular}{ccc}
\hline \multicolumn{1}{c}{ Date } & Relative count & $\begin{array}{c}\text { Converted algal biomass } \\
\text { (mg/L) }\end{array}$ \\
\hline \multicolumn{3}{c}{ Algal group or genera-Diatoms/Chrysophytes } \\
(Bacillariophyta/Chrysophyta)
\end{tabular}

\begin{tabular}{ccc}
\hline Date & Relative count & $\begin{array}{c}\text { Converted algal biomass } \\
\text { (mg/L) }\end{array}$ \\
\hline Algal group or genera-Nonfixing (buoyant) Cyanophyta \\
\hline $2014-05-14$ & 1 & 0.018 \\
$2014-06-18$ & 2 & 0.011 \\
$2014-07-29$ & 31 & 0.721 \\
$2014-08-21$ & 13 & 0.480 \\
$2014-09-17$ & 25 & 0.998 \\
$2014-10-21$ & 1 & 0.002 \\
$2016-05-12$ & 0 & 0.000 \\
$2016-06-01$ & 12 & 0.152 \\
$2016-07-13$ & 36 & 1.214 \\
$2016-08-01$ & 26 & 1.190 \\
$2016-09-12$ & 146 & 4.064 \\
$2016-10-25$ & 143 & 3.199 \\
\hline Algal group or genera-Flagellates (Haptophyta/Cryptophyta) \\
\hline $2014-05-14$ & 3 & 0.054 \\
$2014-06-18$ & 3 & 0.016 \\
$2014-07-29$ & 5 & 0.116 \\
$2014-08-21$ & 8 & 0.295 \\
$2014-09-17$ & 15 & 0.599 \\
$2014-10-21$ & 94 & 0.145 \\
$2016-05-12$ & 70 & 0.129 \\
$2016-06-01$ & 20 & 0.049 \\
$2016-07-13$ & 15 & 0.385 \\
$2016-08-01$ & 13 & 0.566 \\
$2016-09-12$ & 6 & 0.191 \\
$2016-10-25$ & 9 & 0.201 \\
\hline & & \\
\hline
\end{tabular}

\begin{tabular}{lcc}
\multicolumn{3}{c}{ Algal group or genera-Green algae (Chlorophyta) } \\
\hline $2014-05-14$ & 6 & 0.108 \\
$2014-06-18$ & 9 & 0.049 \\
$2014-07-29$ & 9 & 0.209 \\
$2014-08-21$ & 14 & 0.517 \\
$2014-09-17$ & 6 & 0.239 \\
$2014-10-21$ & 3 & 0.005 \\
$2016-05-12$ & 11 & 0.020 \\
$2016-06-01$ & 1 & 0.002 \\
$2016-07-13$ & 4 & 0.103 \\
$2016-08-01$ & 7 & 0.305 \\
$2016-09-12$ & 4 & 0.127 \\
$2016-10-25$ & 5 & 0.112 \\
\hline
\end{tabular}

\begin{tabular}{lcc}
\hline \multicolumn{3}{c}{ Algal group or genera-Fixing Cyanophyta } \\
\hline $2014-05-14$ & 2 & 0.036 \\
$2014-06-18$ & 77 & 0.417 \\
$2014-07-29$ & 14 & 0.325 \\
$2014-08-21$ & 57 & 2.104 \\
$2014-09-17$ & 38 & 1.516 \\
$2014-10-21$ & 0 & 0.000 \\
$2016-05-12$ & 0 & 0.000 \\
$2016-06-01$ & 60 & 0.148 \\
$2016-07-13$ & 40 & 1.026 \\
$2016-08-01$ & 40 & 1.741 \\
$2016-09-12$ & 40 & 1.113 \\
$2016-10-25$ & 9 & 0.201
\end{tabular}


Table 4. Initial constituent concentrations for the Madison Lake CE-QUAL-W2 model: 2014 calibration and 2016 validation runs.

[m NAVD 88, meters above the North American Vertical Datum of 1988; mg/L, milligram per liter; DOM, dissolved organic matter; POM, particulate organic matter; ${ }^{\circ} \mathrm{C}$, degrees Celsius]

\begin{tabular}{lcc}
\hline \multicolumn{1}{c}{ Constituent } & \multicolumn{2}{c}{ Year } \\
\cline { 2 - 3 } & $\mathbf{2 0 1 4}$ & $\mathbf{2 0 1 6}$ \\
\hline Initial water-surface elevation, m NAVD 88 & 310.57 & 340.38 \\
Total dissolved solids, mg/L & 177.7 & 272.0 \\
Dissolved orthophosphate, mg/L & 0.005 & 0.005 \\
Dissolved ammonia, as nitrogen, mg/L & 0.05 & 0.035 \\
Dissolved nitrate plus nitrite, as nitrogen, mg/L & 0.38 & 0.05 \\
Dissolved silica, mg/L & 3.95 & 3.00 \\
Particulate silica, mg/L & 1 & 1 \\
Total iron, mg/L & 0.014 & 0.014 \\
Labile DOM, mg/L & 4.9510 & 3.6759 \\
Refractory DOM, mg/L & 11.5522 & 8.5772 \\
Labile POM, mg/L & 0.1490 & 0.2651 \\
Refractory POM, mg/L & 0.3478 & 0.6186 \\
Diatoms/Chrysophyta, mg/L & 1.4 & $2.5 \times 10^{-12}$ \\
Chlorophyta (green algae), mg/L & $5.0 \times 10^{-9}$ & 0.0300 \\
Fixing cyanophyta, mg/L & $8.0 \times 10^{-6}$ & 0.0035 \\
Nonfixing (buoyant) cyanophyta, mg/L & $7.5 \times 10^{-13}$ & 0.0010 \\
Haptophyta/Cryptophyta, mg/L & $1.0 \times 10^{-7}$ & 0.1500 \\
Dissolved oxygen, mg/L & ${ }^{1} 0.75-10.25$ & 10 \\
Inorganic carbon, mg/L & 170.4 & 182.2 \\
Alkalinity, mg/L & 140.0 & 149.7 \\
Labile phosphorus partition & 0.0065 & 0.0065 \\
Labile nitrogen partition & 0.0950 & 0.0950 \\
Refractory phosphorus partition & 0.0065 & 0.0065 \\
Refractory nitrogen partition & 0.0950 & 0.0950 \\
Initial temperature, ${ }^{\circ} \mathrm{C}$ & 9.9 & 6.0 \\
Sediment temperature, ${ }^{\circ} \mathrm{C}$ & 14.5 & 0.4 \\
Macrophyte, mg/L & 5.0 & \\
\hline
\end{tabular}

${ }^{1}$ Initial constituent concentrations were considered uniform throughout the lake for every segment and layer, except in cases with a reported range of values, which constitutes a vertical profile. The highest value is at the surface layer, the lowest value is at the bottom layer, and iterative values are in between for each of the layers. 


\section{Model Calibration and Validation}

The goodness of fit between the simulated results and measured lake values was considered during model calibration. The two values used to evaluate the degree of fit were the mean absolute error (MAE) and the root mean square error (RMSE). The MAE, computed by equation 3 (for example, see use in Smith and others [2017, 2018]), is a measure of the mean difference between the simulated (model) value and the measured value:

MAE $=\frac{1}{n} \sum_{i=1}^{n} \mid$ simulated value - measured value $\mid$

where

$n \quad$ is the number of observations and

$i \quad$ is the index of summation.

For example, an MAE of 1.0 milligram per liter $(\mathrm{mg} / \mathrm{L})$ for DO means that the simulated value is, on average, within $1.0 \mathrm{mg} / \mathrm{L}$ of the measured DO value. The RMSE is a slightly different metric in that it indicates the amount of deviation between the simulated value and the measured value. The RMSE, as computed by equation 4 (for example, see use in Smith and others [2014]), gives the deviation between the simulated value and the measured value about 67 percent of the time:

RMSE $=\sqrt{\frac{1}{n} \sum_{i=1}^{n}{ }^{2}(\text { simulated value }- \text { measured value })^{2}}$

where

$$
n \quad \text { is the number of observations and }
$$$$
i \quad \text { is the index of summation. }
$$

The goodness of fit between the simulated and measured outlet water-surface elevation was only considered during the initial water balance calibration for each year. The early focus on the water balance made certain that the amount of flow in and out of the lake is properly considered before the subsequent water temperature, DO, algae, and nutrients followed, using the MAE and RMSE metrics. Refined calibration focused on the vertical profiles of temperature and DO. Additionally, the refined calibration step included the water-quality parameters highlighted previously (ammonia, nitrate plus nitrite, total Kjeldahl nitrogen, total phosphorus, orthophosphate, and chlorophyll $a$ ). Final refinement of model parameters was achieved with the realization of low MAE and RMSE values for most of the target constituents. Values of MAE and RMSE below 1 degree Celsius $\left({ }^{\circ} \mathrm{C}\right)$ and $<1 \mathrm{mg} / \mathrm{L}$ for DO were ideal but not possible for every profile. The MAE and RMSE values for other water-quality parameters were operationally defined by other USGS reports using CE-QUAL-W2, such as Smith and others (2014), which included Lake Carlos, Elk Lake, and Trout Lake, and Smith and others (2017), which included the original Madison Lake model and Pearl Lake.
Most model runs included one adjustment and a subsequent model run to characterize the parameter sensitivity.

\section{Water Balance}

The CE-QUAL-W2 model requires differences between simulated and measured water-surface elevations to be rectified to achieve a water balance. The 2014 water balance was completed during the initial model calibration, and the 2016 water balance was completed during model validation. Similar to the calibration strategy for 2014 (Smith and others, 2017), the initial attempt to achieve a water balance for 2016 used the two gaged tributaries, the northeast inlet and southeast inlet (table 1), as the sole inflows for the calibration period of March 30-November 23, 2016. However, the simulated watersurface elevation was below the measured water-surface elevation, which indicated that either additional water sources to the lake existed, such as ungaged tributaries and groundwater, or the 2014 rating and daily observer points underestimated the inflows from the two inlets.

A total of 2 distributed tributary flows were added iteratively for each of the 2 Madison Lake branches to include unaccounted inflow. In addition to unaccounted inflows and groundwater flow, the 2016 water balance included a higher percentage of distributed tributary flow compared to the ratio of branch inflows to distributed tributary flow in 2014. For 2014, about 15 percent of the total flow during the calibration period (May 15-November 1, 2014) was from the distributed tributary flow. Alternatively, about 51 percent of the total flow during the validation period (March 30-November 23, 2016) was from the distributed tributary flow. A comparison between daily flows calculated directly from the transducer water levels and daily flows calculated from the 2014 Lake Level Minnesota Monitoring Program yielded an $R^{2}$ of 0.98 and 0.97 , respectively, for branch 1 inflow and branch 2 inflow, demonstrating that using the lake water-surface elevation rather than transducer water levels was an appropriate technique for 2016. However, the lack of subdaily resolution combined with the possibility of bias from using the lake water-surface elevation led to the higher percentage of distributed tributary flow for 2016. The water balance was still rectified for 2016, with MAE and RMSE values of $<0.03 \mathrm{~m}$ for the simulated watersurface elevations.

\section{Temperature}

The simulated water temperature results from the calibration (2014) and validation (2016) periods were compared to vertical profiles of lake water temperatures at the southwest deep point site, generally collected during MNDNR waterquality sampling trips. Comparisons to the same 2014 profiles were made for the original Madison Lake model calibration (Smith and others, 2017), but new comparisons were 
warranted to make sure that the updated model adequately captured the temperature dynamics of the lake.

The simulated and measured vertical profiles of lake water temperatures for a total of eight dates from 2014 are shown in figure 2, and nine dates from 2016 are shown in figure 3 . The temperature calibration did not differ much from the original Madison Lake model. For the combined 2014 vertical profiles, the MAE and RMSE values of the updated model were 0.55 and $0.70{ }^{\circ} \mathrm{C}$, respectively (table 5), compared to 0.53 and $0.68{ }^{\circ} \mathrm{C}$, respectively, for the original Madison Lake model. As with the original model, the location and slope of the simulated thermocline matched the measured thermocline. For 2016, the model also consistently attained MAE and RMSE values $<1.0^{\circ} \mathrm{C}$ for eight of nine dates, with one exception early in the year, May 24, that was simulated slightly too warm. For the combined 2016 vertical profiles, the MAE and RMSE values were 0.67 and $0.81{ }^{\circ} \mathrm{C}$, respectively (table 5).

The boundary conditions that affect water temperature included sediment temperature, initial lake water temperature, and inflow water temperature. The temperature substitution for 2016, using air temperatures to simulate water temperatures, did not seem to have a large effect on the 2016 model
May 22, 2014

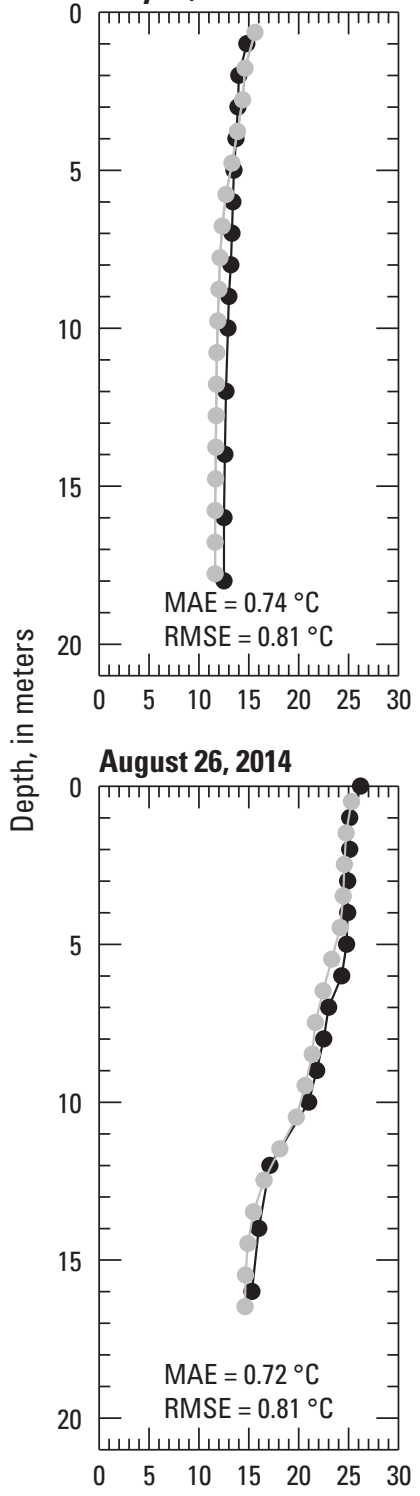

May 29, 2014

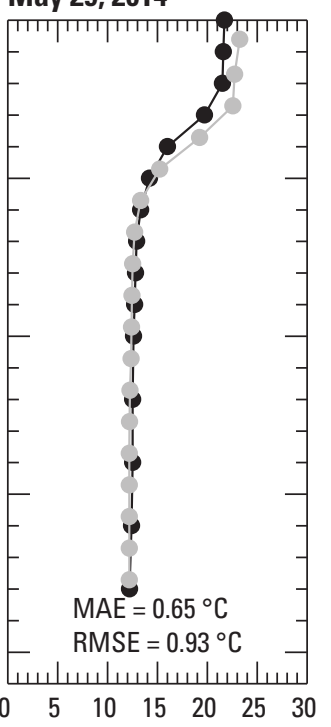

September 17, 2014

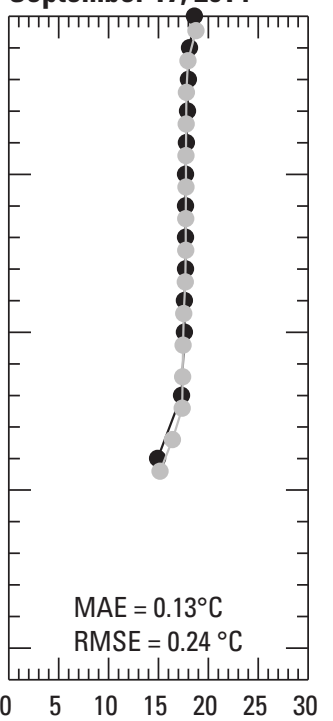

June 3, 2014

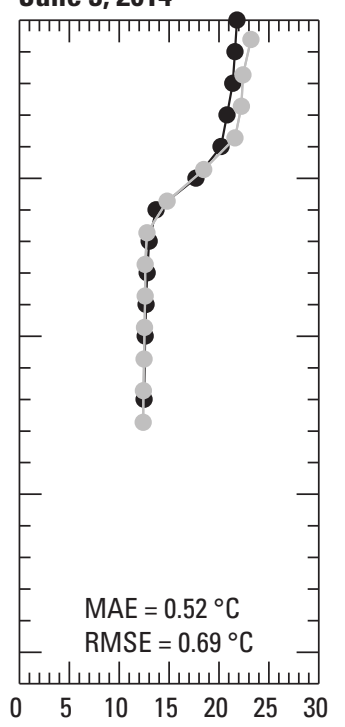

July 9, 2014

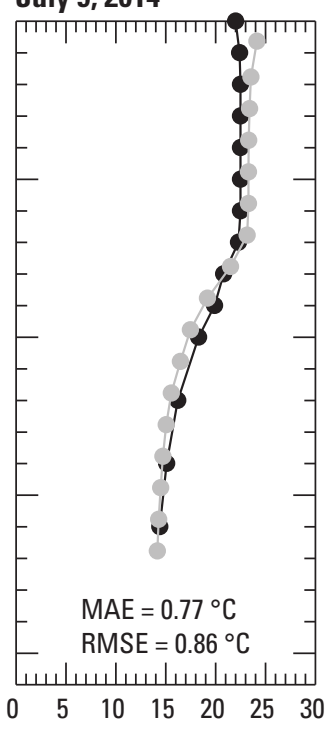

August 1, 2014

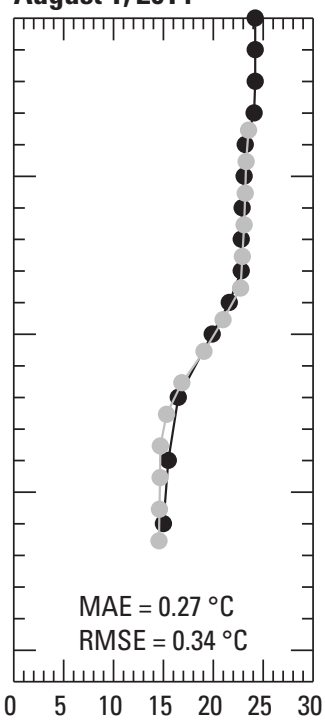

October 15, 2014

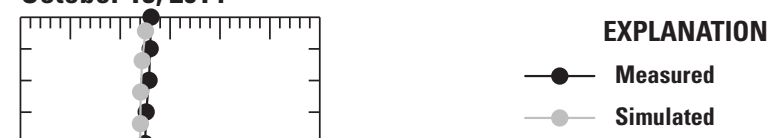

Temperature, in degrees Celsius $\left({ }^{\circ} \mathrm{C}\right)$

Figure 2. Simulated and measured water temperature for vertical profiles at Madison Lake southwest deep point near Madison Lake, Minnesota, for eight dates in 2014, with values of mean absolute error (MAE) and root mean square error (RMSE). 
validation given the low MAE and RMSE values. Meteorological effects include air temperature, wind velocity, wind direction, and solar radiation. Wind sheltering effects, as augmented through the wind sheltering coefficient input file, were still important for the 2016 validation. The wind sheltering coefficient input file considers boundary effects on wind mixing, such as topography and shoreline tree cover, with a range from 50 to 64 percent of the full wind value for 2014 and 50 to 72 percent for 2016, except for a value of 100 percent at the beginning of both years. Several hydraulic and thermal parameters also affect water temperature. Most of these parameters were left identical to the original Madison Lake model, with the exception of an increase from 1.5 to 2.0 for the CBHE coefficient (table 4 of Smith and others [2017]), which is the coefficient that controls sediment heat exchange, and a slight increase in the sediment temperature by $0.3{ }^{\circ} \mathrm{C}$. Other critical parameters altered for the updated model were the short wave solar radiation extinction coefficients because of various algal groups (EXA1, EXA2, EXA3, EXA4, EXA5), which were all adjusted from 0.1 to the recommended default CE-QUAL-W2 value of 0.2 for each group (Cole and Wells, 2015; Smith, 2019).
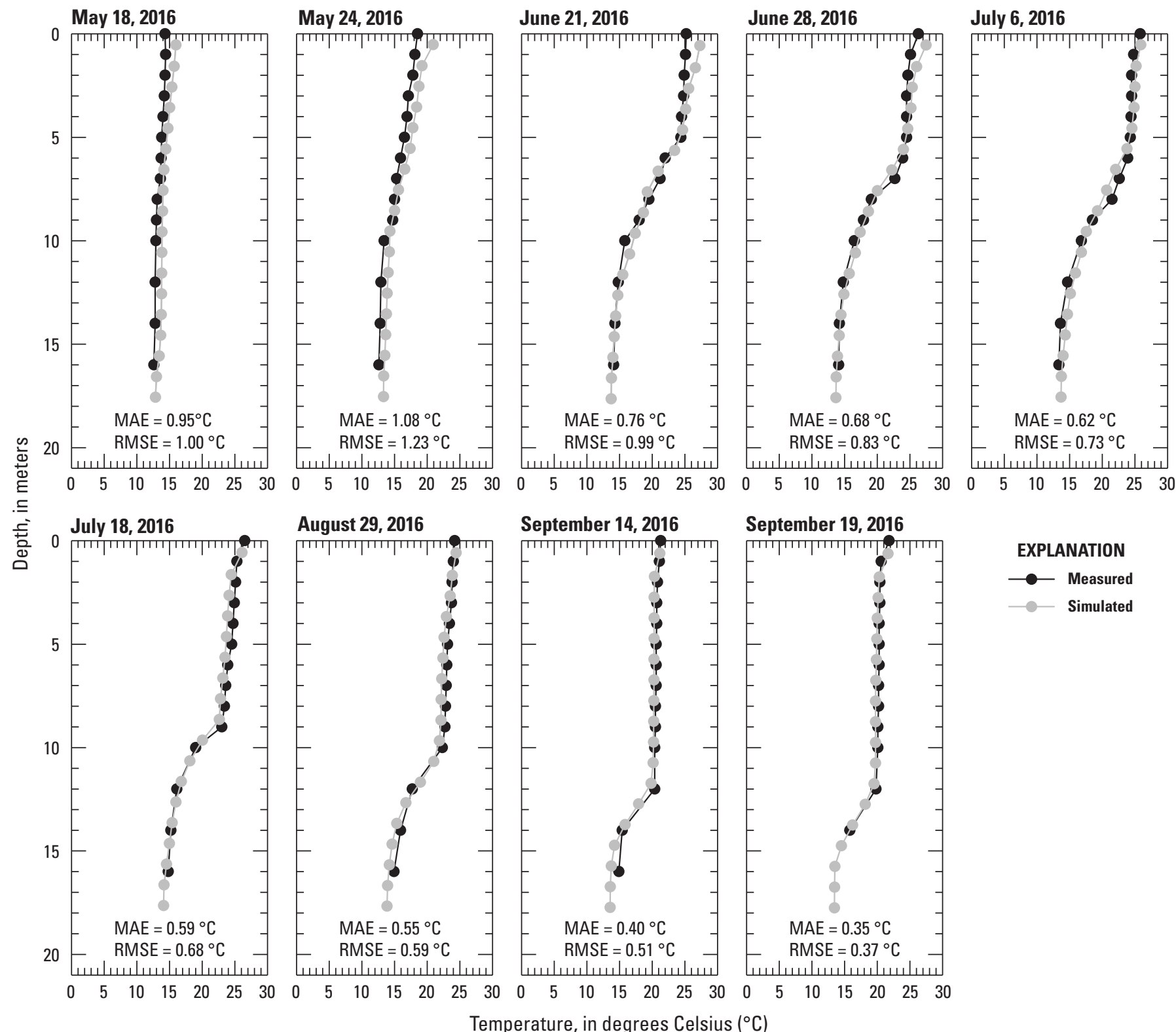

EXPLANATION

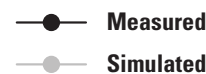

Temperature, in degrees Celsius $\left({ }^{\circ} \mathrm{C}\right)$

Figure 3. Simulated and measured water temperature for vertical profiles at Madison Lake southwest deep point near Madison Lake, Minnesota, for nine dates in 2016, with values of mean absolute error (MAE) and root mean square error (RMSE). 
Table 5. Summary of mean absolute error (MAE) and root mean square error (RMSE) values for calibration (2014) and validation (2016) runs for Madison Lake at Madison Lake southwest deep point near Madison Lake, Minnesota.

$\left[{ }^{\circ} \mathrm{C}\right.$, degrees Celsius; Minn. Minnesota; mg $/ \mathrm{L}$, milligram per liter; $<$, less than; $\mu \mathrm{g} / \mathrm{L}$, microgram per liter; multiple, integrated vertical profile data]

\begin{tabular}{|c|c|c|c|c|c|c|c|}
\hline \multirow[b]{2}{*}{ Constituent } & \multirow[b]{2}{*}{$\begin{array}{l}\text { Depth } \\
\text { (meters) }\end{array}$} & \multicolumn{3}{|c|}{ Calibration year (2014) } & \multicolumn{3}{|c|}{ Validation year (2016) } \\
\hline & & $\begin{array}{l}\text { Number of } \\
\text { compared } \\
\text { data points }\end{array}$ & MAE & RMSE & $\begin{array}{l}\text { Number of } \\
\text { compared } \\
\text { data points }\end{array}$ & MAE & RMSE \\
\hline Water temperature, ${ }^{\circ} \mathrm{C}$ & multiple & 103 & 0.55 & 0.70 & 125 & 0.67 & 0.81 \\
\hline Dissolved oxygen, mg/L & multiple & 103 & 0.86 & 1.22 & 125 & 0.91 & 1.46 \\
\hline Chlorophyll $a$, mg/L & 1 & 6 & 22 & 29 & 10 & 26 & 31 \\
\hline Dissolved orthophosphate, mg/L & 1 & 6 & 0.02 & 0.02 & 5 & 0.02 & 0.02 \\
\hline Dissolved ammonia, mg/L & 1 & 6 & 0.17 & 0.33 & 5 & 0.01 & 0.02 \\
\hline Dissolved nitrate plus nitrite, as nitrogen, $\mathrm{mg} / \mathrm{L}$ & 1 & 6 & 0.02 & 0.03 & 10 & 0.03 & 0.04 \\
\hline Total Kjeldahl nitrogen, mg/L & 1 & 6 & 0.35 & 0.43 & 11 & 0.20 & 0.24 \\
\hline Total phosphorus, $\mu \mathrm{g} / \mathrm{L}$ & 1 & 6 & 80 & 77 & 10 & 52 & 53 \\
\hline Total phosphorus, $\mu \mathrm{g} / \mathrm{L}$ & $\begin{array}{l}16.7(2014) \\
15.5(2016)\end{array}$ & 6 & 22 & 29 & 5 & 65 & 70 \\
\hline $\begin{array}{l}\text { Diatoms/chrysophytes } \\
\text { (Bacillariophyta/Chrysophyta), mg/L }\end{array}$ & 1 & 6 & 0.34 & 0.46 & 6 & 0.36 & 0.44 \\
\hline Green algae (Chlorophyta), mg/L & 1 & 6 & 0.12 & 0.13 & 6 & 0.28 & 0.39 \\
\hline Fixing Cyanophyta, mg/L & 1 & 6 & 0.45 & 0.50 & 6 & 0.13 & 0.19 \\
\hline Nonfixing (buoyant) Cyanophyta, mg/L & 1 & 6 & 0.74 & 1.03 & 6 & 0.81 & 1.02 \\
\hline Flagellates (Haptophyta/Cryptophyta), mg/L & 1 & 6 & 0.13 & 0.17 & 6 & 0.19 & 0.23 \\
\hline
\end{tabular}

\section{Dissolved Oxygen}

Accurately simulating DO is critical in determining the size of summer habitat refugia for important game fish species because thermal requirements often confine fish species below the epilimnion where they are vulnerable to mass die offs because of a lack of DO. Often, fish either must exceed their thermal tolerance to get enough DO or risk low DO waters. Also, the fish potentially stay in a constant state of stress by expending more energy when moving between suboptimal habitats. If these fish subsist for long periods in warmer waters in combination with low DO levels, even warmwater fish can be subject to die offs (Fang and others, 1999).

Within the CE-QUAL-W2 model, many sources and sinks are available for DO, which likely makes DO the most complicated constituent to model. Sources include inflows, atmospheric exchange across the lake surface, and algal photosynthesis (Cole and Wells, 2015). Sinks include decay mechanisms such as bacterial respiration of dissolved and solid-phase organic matter (labile and refractory) in the water column and lake sediment. Other simulated sinks include algal respiration, macrophyte respiration, ammonia and nitrite nitrification, and exchange back to the atmosphere and into sediments (Cole and Wells, 2015). The values used for these parameters are part of the CE-QUAL-W2 control file (Smith, 2019).
With varying success, the model captured the trajectories of DO concentrations at multiple depths over time, which indicated that the model was accurately simulating the underlying metabolic processes in each lake. For the DO calibration (2014) and validation (2016), the principal calibration targets were the lake profile data from the southwest deep point site, available from monthly vertical DO profiles collected by MNDNR personnel during water-quality sampling trips. Generally, DO measurements were recorded for each meter below water surface. Simulated and measured DO concentrations are shown for a total of eight dates for 2014 (fig. 4) and a total of nine dates for 2016 (fig. 5). Overall, the simulated DO concentrations tracked the measured concentrations from the southwest deep point site.

Similar to water temperature, the same 2014 DO profiles were compared for the original Madison Lake model calibration (Smith and others, 2017), but new comparisons were warranted to make sure that the updated model adequately captured DO dynamics within the lake. Generally, where the greatest change in $\mathrm{DO}$ occurred, the simulated concentrations matched the depth and slope of the measured concentrations. Also, compared to the original model comparisons, the same observations and conclusions from Smith and others (2017) can be made for the updated model calibration (2014); for example, the midwater DO maximum between 3 and $6 \mathrm{~m}$ on May 29, 2014, was captured by the updated model, as 

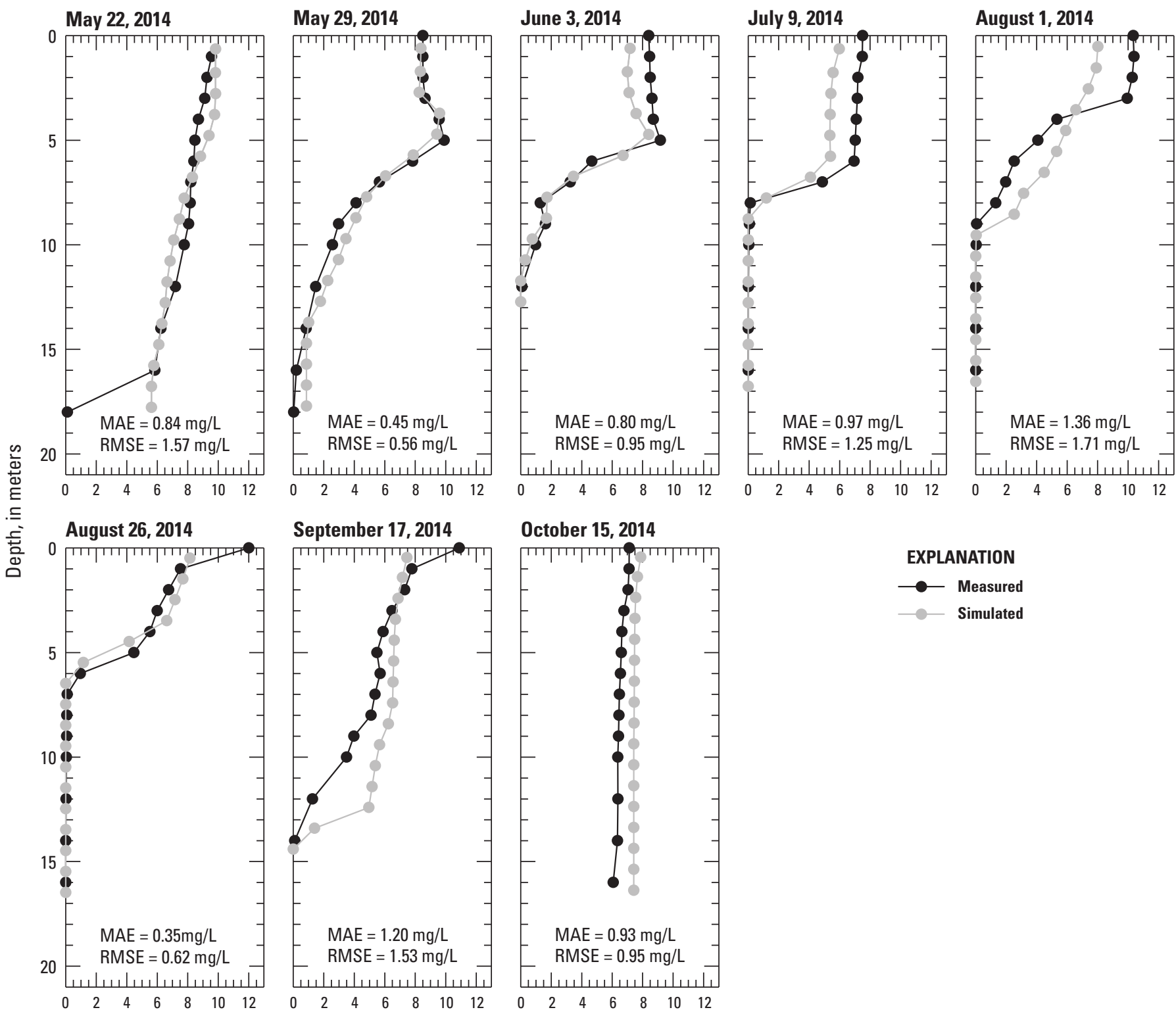

Dissolved oxygen concentration, in milligrams per liter ( $\mathrm{mg} / \mathrm{L}$ )

Figure 4. Simulated and measured dissolved oxygen concentration vertical profiles at Madison Lake southwest deep point near Madison Lake, Minnesota, for eight dates in 2014, with values of mean absolute error (MAE) and root mean square error (RMSE).

reflected with the low MAE and RMSE values $(<0.6 \mathrm{mg} / \mathrm{L}$; fig. 4). Minimal hypolimnion oxygen levels starting from around June 3, 2014, were maintained until sometime between the August 26 and September 17 DO profiles, and similar results were obtained in the original model. By September 17, the lake began to turn over, as shown for DO (fig. 4) and lake water temperature (fig. 2). The simulated DO concentrations for September 17 were greater at depth, so the lake turnover started 7 to 10 days earlier in the model simulation than in the measured lake values. For the combined 2014 vertical DO profiles, the MAE and RMSE values were 0.86 and $1.22 \mathrm{mg} / \mathrm{L}$, respectively (table 5), compared to the original Madison Lake model with 0.68 and $1.15 \mathrm{mg} / \mathrm{L}$, respectively.

For the 2016 validation, the simulated DO still closely matched measured DO values, but MAE and RMSE values were higher than values obtained during calibrations using 2014 data (table 5). For the combined 2016 vertical profiles, the MAE and RMSE values were 0.91 and $1.46 \mathrm{mg} / \mathrm{L}$, respectively; however, despite these higher values, the model simulated the general DO trajectories throughout the year from May to September with the nine profiles (fig. 5). The largest discrepancy between the measured and simulated results was 

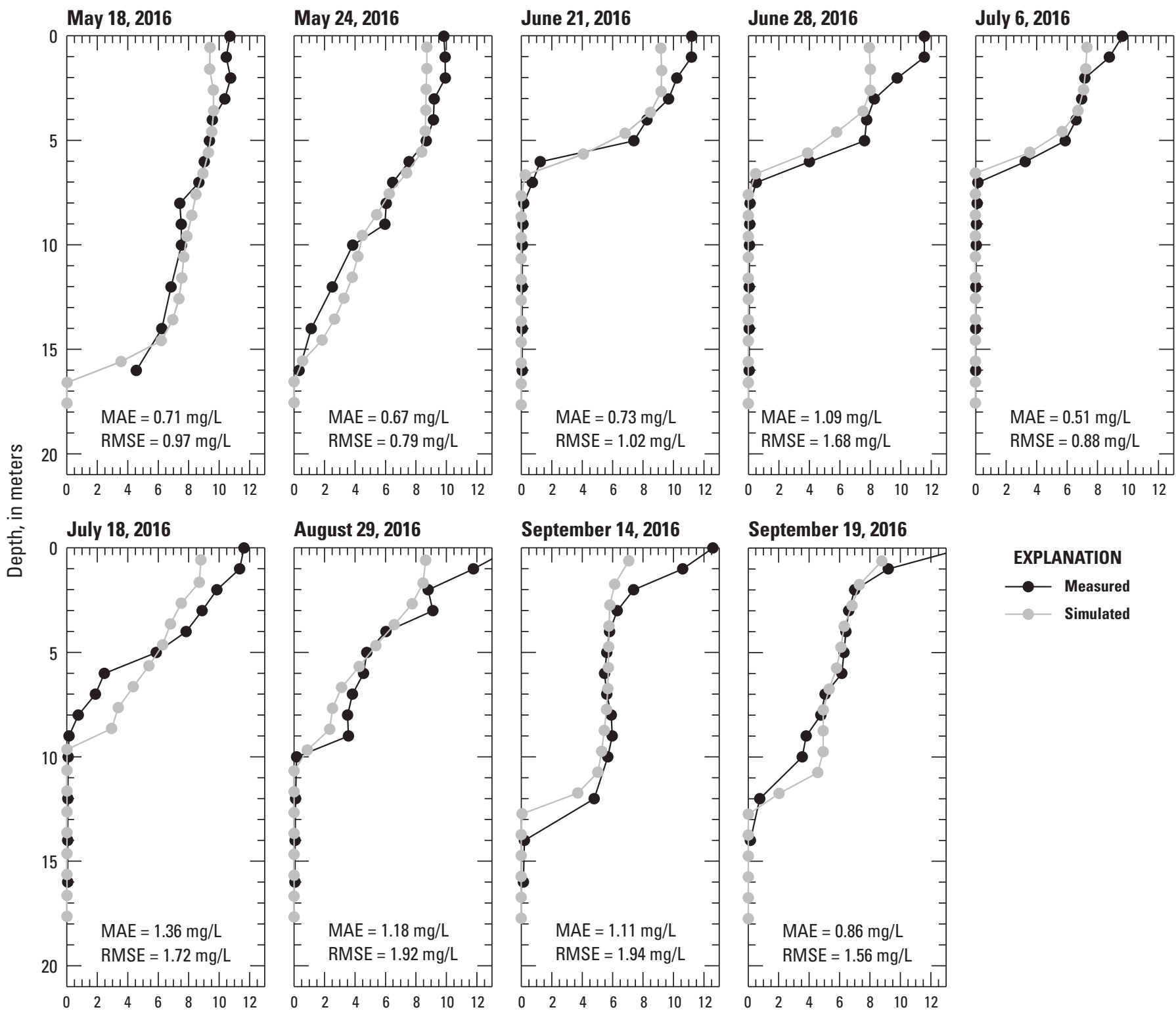

Dissolved oxygen concentration, in milligrams per liter $(\mathrm{mg} / \mathrm{L})$

Figure 5. Simulated and measured dissolved oxygen concentration vertical profiles at Madison Lake southwest deep point near Madison Lake, Minnesota, for nine dates in 2016, with values of mean absolute error (MAE) and root mean square error (RMSE).

the lack of simulated DO supersaturation in the shallower mixed layer. This discrepancy could be caused by the lack of simulated algal growth earlier in the year, such that an earlier algal bloom missed or not captured with the model would have caused larger simulated DO values in the shallow mixed layer. Alternatively, the model adequately simulated the depth and timing of hypolimnetic oxygen minimums. Overall, the 2016 model validation indicated that the model could capture DO dynamics for two years with different algal community dynamics and a different total algal biomass.

Substantial changes were made to the algal community dynamics parameters in the updated model. Algal dynamics that played a large part in controlling the DO dynamics are described separately in the following "Algae" section; however, other major parameters that can control limnological DO concentrations, such as the decay rates of different organic matter pools, were unaltered from the original Madison Lake model. Also, the sediment oxygen demand (parameter SOD) was unaltered from the original Madison Lake model ( $2.5 \mathrm{mg} / \mathrm{L})$. The equation for calculating reaeration was changed from equation 9 to equation 3 (Cole and Wells, 2015, p. B54-B55) upon a determination that equation 3 is more appropriate for water bodies with lower flow-through rates. 


\section{Algae}

The original model version simulated phytoplankton into four general algal communities or groups: (1) Bacillariophyta (diatoms) and Chrysophyta (chrysophytes); (2) Chlorophyta (green algae); (3) Cyanophyta (blue-green algae); and, (4) Haptophyta and Cryptophyta (flagellates). However, algal group dynamics within CE-QUAL-W2 models are sensitive and the uncertainty in model parameterization beyond four algal groups can be problematic (Cole and Wells, 2015). Therefore, the Cyanophyta group was divided into two groups in the updated model: a nitrogen-fixing Cyanophyta group, generally representative of Anabaena, Dolichospermum, and Cylindrospermopsis, and a nonfixing, buoyant Cyanophyta group, generally representative of Planktothrix, Microcystis, and Woronichinia. The Cyanophyta group was divided to improve the ability of the model to predict Cyanophyta blooms and to focus the model on Cyanophyta populations known to exist in Madison Lake. The updated model and chlorophyll $a$ data indicated that Cyanophyta dominated Madison Lake starting in mid- to late summer in 2014 and 2016. These results support the findings of the original model that only included 2014 data (Smith and others, 2017); furthermore, an analysis of algal data going back to 2013 indicated Cyanophyta dominance in the mid- to late-summer months (Minnesota Pollution Control Agency, 2018).

Simulating beyond three to four algal groups within CE-QUAL-W2 can be challenging. The model updates to the algal community submodule required substantial adjustments to many of the parameters governing algal growth and senescence for all five groups. Also, the lack of measured Madison Lake algal data beyond algal counts and biomass did not adequately constrain model parameterization independently. Instead, the guidance for determining algal growth patterns was mainly provided by other CE-QUAL-W2 modeling efforts (Smith and others, 2014, 2017) and the Lake St. Croix CE-QUAL-W2 model (Smith and others, 2018).

In both model versions, zooplankton grazing dynamics were captured within algal specific constants such as the algal growth rate (parameter AG) and the algal mortality rate (parameter AM; Smith, 2019). Algal growth temperature ranges (parameters AT1 through AT4), algal growth rates (parameter AG), and the light saturation intensities at the maximum photosynthetic rate (parameter ASAT) were different across all five algal groups. In contrast, one major change from the original Madison Lake model was the fraction of algal growth specific to temperature ranges (parameters AK1 through AK4). Rather than adjust these parameters to artificially attain a better model fit, these parameters were set to the CE-QUAL-W2 default rates because we lacked sufficient information on these parameters. Other algal growth parameters were also set with more uniformity across the different groups, given the lack of specific information for the Madison Lake algal groups. With the updated model, the stoichiometric equivalences used for determining the nutrients in the algal biomass, such as phosphorus, nitrogen, and carbon, were also set with more uniformity across the different algal groups and generally closer to the CE-QUAL-W2 default rates. Most importantly, the ratio between algal biomass and chlorophyll $a$ was adjusted to 0.05 across all groups rather than different ratios between the groups, and this same adjustment was made for the transformation of the measured algal data conversions to biomass.

Overall, distributing algae among five groups instead of four (fig. 6) improved the ability to model the algal dynamics of Madison Lake using the updated model (Smith and others, 2017). The algae MAE and RMSE values dropped across all five algal groups compared to the algal group simulations for the original model. The largest change in the MAE and RMSE values was for Cyanophyta. In the original report, Cyanophyta (referred to as "blue-green algae") had MAE and RMSE values of 1.81 and $1.95 \mathrm{mg} / \mathrm{L}$, respectively, whereas the updated model split this group into two groups with MAE and RMSE values of $<1.1 \mathrm{mg} / \mathrm{L}$ (table 5 ).

For the 2014 calibration year, diatoms/chrysophytes were the first group to peak, as indicated with the simulated and measured values. Diatoms/chrysophytes commonly peak earlier in the year (Sigee, 2005). The simulated diatom values peaked by the middle of May and then approached $0 \mathrm{mg} / \mathrm{L}$ by late June. For the measured values, a second peak occurred in late July and again in mid-September; however, the model did not capture these dynamics. Several factors controlled the lack of simulated diatom growth beyond early June. Simulated algal growth favored the other groups beyond the early part of the year. The temperature range for optimal diatom growth was lower than the other algal groups so, once the lake warmed by early June, the diatoms/chrysophytes were outside their thermal range for optimal growth; furthermore, the larger algal light saturation intensity for diatoms/chrysophytes limited growth once the lake had greater concentrations of suspended sediments and algal biomass blocking the light. Combined with a larger settling rate, the diatoms/chrysophytes would have settled to a depth in the lake unfavorable for optimal light saturation set in the model.

The next group to succeed diatoms/chrysophytes in 2014 was the fixing Cyanophyta (fig. 6). Splitting up Cyanophyta into at least two groups was warranted because nitrogen limitation at this time of year combined with warmer temperatures favored Cyanophyta capable of fixing nitrogen (Smith and others, 2017). The wider temperature range for maximum algal growth (between 20 and $30^{\circ} \mathrm{C}$ ) combined with a lower algal light saturation intensity of 75 watts per square meter $\left(\mathrm{W} / \mathrm{m}^{2}\right)$ compared to $120 \mathrm{~W} / \mathrm{m}^{2}$ for the diatoms/chrysophytes allowed for more growth of fixing Cyanophyta (Anabaena, Dolichospermum, and Cylindrospermopsis). Less emphasis was placed on other factors compared to the original model.

By mid-July, the light saturation and favorability for fixing Cyanophyta growth began to wane in favor of the nonfixing Cyanophyta group (Planktothrix, Microcystis, and Woronichinia). This algal group had a higher light saturation intensity $\left(125 \mathrm{~W} / \mathrm{m}^{2}\right)$ and higher buoyancy (settling rate of 0 ) compared to the fixing Cyanophyta group in the 
CE-QUAL-W2 model. Throughout the open water period, the nonfixing Cyanophyta group continued to grow and the fixing Cyanophyta group died off. Measured data generally supported simulated growth, except that simulated total Cyanophyta biomass decreased in September whereas measured total Cyanophyta biomass increased in September and decreased in October. Differentiation of Cyanophyta groups was difficult to simulate in the 2014 calibration, but for the 2016 validation, the dynamics seemed to be closer to the measured data, as described later in this section.

The other two algal community groups, green algae and flagellates, had similar growth rates and patterns for the simulated and measured values in 2014. The two groups were distinguished from each other in that the green algae demonstrated a mid-August peak, whereas the flagellates demonstrated a September peak (fig. 6). The maximum algal growth temperature range was similar for both groups, with 20-25 ${ }^{\circ} \mathrm{C}$ and $24-28{ }^{\circ} \mathrm{C}$ for the green algae and flagellates, respectively. Of the five groups, the flagellates had the lowest algal light saturation intensity of $20 \mathrm{~W} / \mathrm{m}^{2}$. Otherwise, as documented in the CE-QUAL-W2 control file (Smith, 2019), the parameterization of the two groups was similar for the growth rate, algal mortality (parameter AM), and algal settling rate, and both groups had the same algal half-saturation constants for nitrogen- and phosphorus-limited growth (parameter AHSP).

Overall, the simulated algal biomass concentrations for the calibration were similar to measured algal biomass concentrations with the exception of the previously described deviation for diatoms/chrysophytes later in the year. Also,

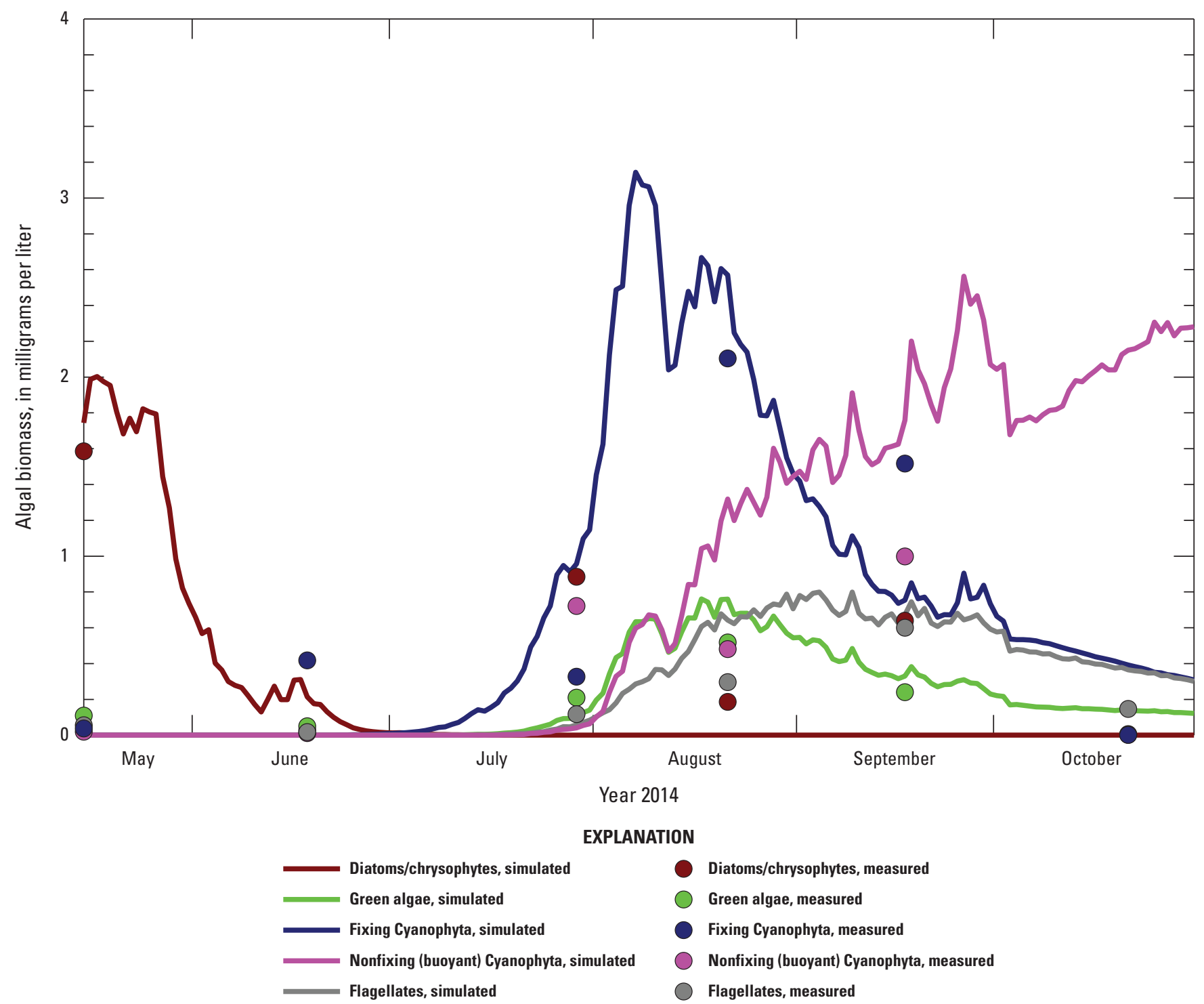

Figure 6. Simulated and measured algal group distributions (diatoms/chrysophytes, green algae, fixing Cyanophyta, nonfixing [buoyant] Cyanophyta, and flagellates) for the 1-meter depth at Madison Lake southwest deep point near Madison Lake, Minnesota, May 15 to November 1, 2014. 
the simulated Cyanophyta concentrations did not match the large measured values in August and September, although the combined simulated growth of the fixing and nonfixing Cyanophyta groups did match the measured values. Part of the likely discrepancy is that isolated sample points in time might not capture the general trend.

Chlorophyll $a$ concentration data were used to help interpret if the overall magnitude of the composite algal community was in the correct range. Photosynthetic pigments, such as chlorophyll $a$, are accepted in the literature as surrogates for algal biomass given the large expense of measuring algal biomass directly (Lindenberg and others, 2008). Simulated and measured values of the chlorophyll $a$ concentrations are shown for the Madison Lake southwest deep point site in figure 7 (segment 7, fig. 1). Measured chlorophyll $a$ data were collected in the surface layer about $1 \mathrm{~m}$ below the water surface as part of the monthly MNDNR water-quality sampling trips. Overall, the simulated values were a good approximation of the measured values, with the exception of the high simulated chlorophyll $a$ concentration compared to the low measured chlorophyll $a$ concentration in October.

Considerable differences occurred in terms of algal growth (fig. 8) and chlorophyll $a$ for the 2016 validation compared to 2014. Unlike 2014, the simulated growth of green algae and flagellates occurred much earlier in the year than indicated by the measured data (fig. 8). Simulated diatom growth also occurred at a much lower rate than in
2014. Simulated growth of the two Cyanophyta groups started earlier in the year, but simulated growth was also supported by the measured data. The simulated fixing Cyanophyta peaked in July at the same time as the measured fixing Cyanophyta, and the nonfixing (buoyant) Cyanophyta demonstrated the same growth curve as 2014, except with an earlier start. The simulated nonfixing Cyanophyta overall seemed to grow faster than the measured nonfixing Cyanophyta, but this could also be caused by a model limitation. The CE-QUAL-W2 model generally might have a difficult time distinguishing different nitrogen sources (organic versus nonorganic sources); furthermore, the fixing Cyanophyta group does not necessarily fix nitrogen at all times because nitrogen fixation is a highly energetic process (Maier, 2004). However, within the CE-QUAL-W2 modeling framework, the fixing Cyanophyta group cannot be setup to fix nitrogen only part of the time; therefore, the interplay of nitrogen fixation versus nonnitrogen fixation among different Cyanophyta groups can be difficult to simulate. As with 2014, the chlorophyll $a$ concentration data were used to help interpret if the overall magnitude of the algal group composition was in the correct range for 2016 (fig. 9). Similar to 2014, changes in simulated chlorophyll $a$ values closely followed changes in measured values, but simulated values consistently were lower than the measured data in the later summer mainly because the model did not capture the measured nonfixing Cyanophyta growth.

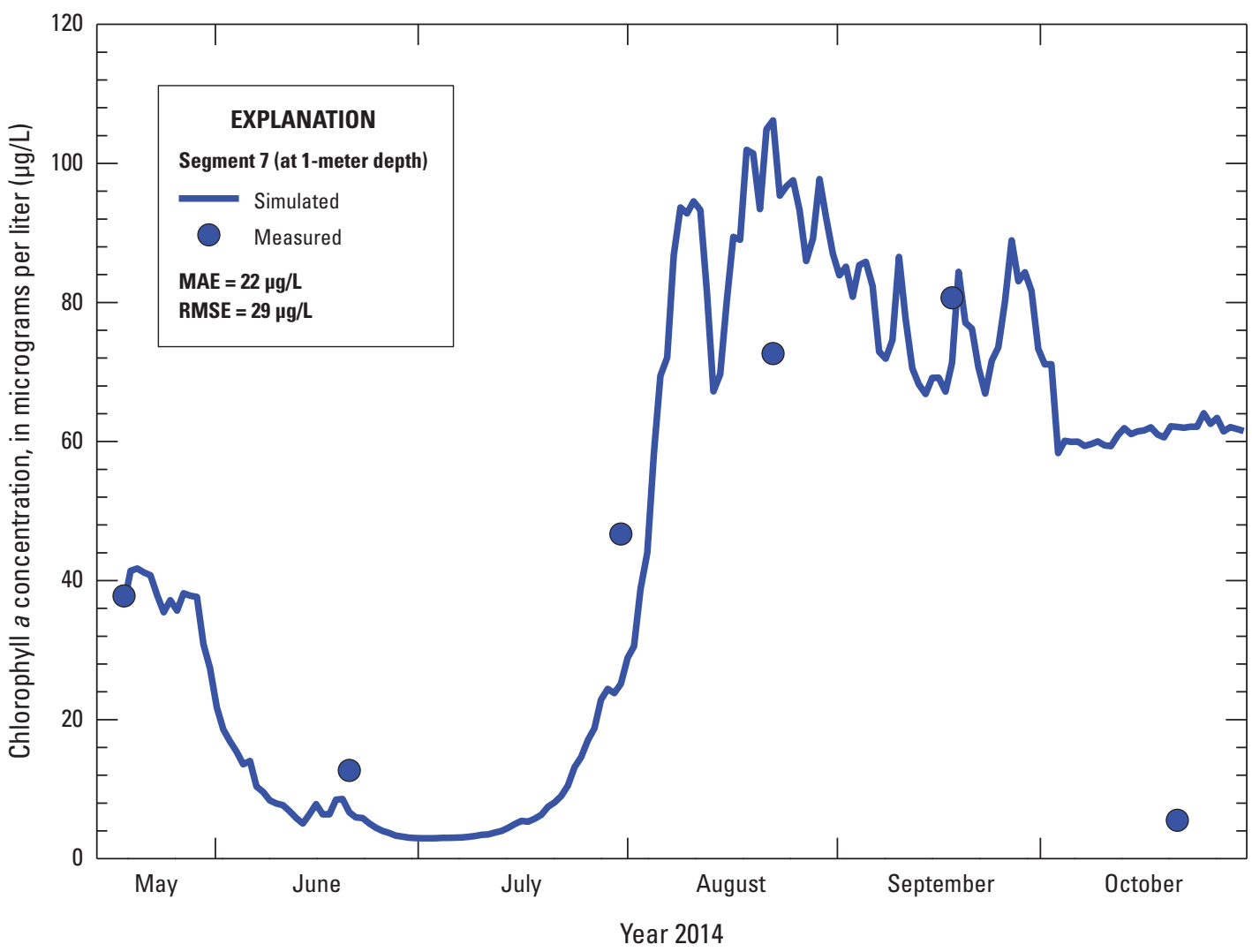

Figure 7. Simulated and measured chlorophyll a concentrations for the 1-meter depth at Madison Lake southwest deep point near Madison Lake, Minnesota (segment 7), May 15 to November 1, 2014. 


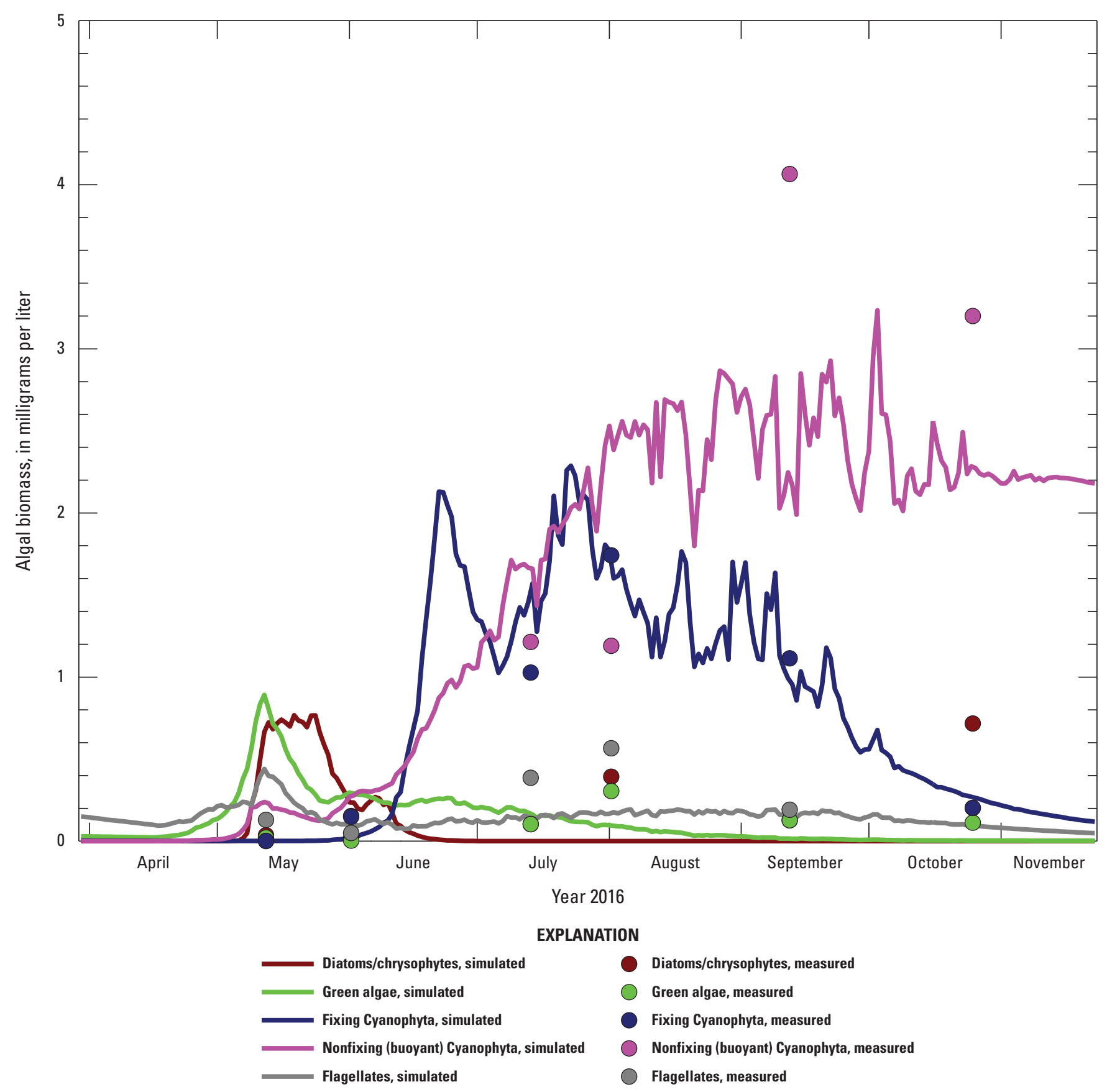

Figure 8. Simulated and measured algal group distributions (diatoms/chrysophytes, green algae, fixing Cyanophyta, nonfixing [buoyant] Cyanophyta, and flagellates) for the 1-meter depth at Madison Lake southwest deep point near Madison Lake, Minnesota, March 30 to November 23, 2016.

\section{Macrophyte Growth}

The macrophyte growth model was run for the 2014 calibration and 2016 validation because a previous study documented high macrophyte growth in Madison Lake (Lindon and others, 2010). Most macrophyte growth parameters were kept at default rates except for the maximum macrophyte growth rate (parameter MG), the light saturation intensity at maximum photosynthetic rate (parameter MSAT), and the fraction of macrophyte biomass that is converted to particulate organic matter after macrophytes die (parameter MPOM; Smith and others [2017]). However, two adjustments were made to the macrophyte growth module from the original Madison Lake CE-QUAL-W2 model. For the original model (Smith and others, 2017), the fractions of phosphorus (parameter PSED) and nitrogen uptake (parameter NSED) from sediments were set equal to 1 , but for the updated model, both parameters were adjusted to 0.5 . 


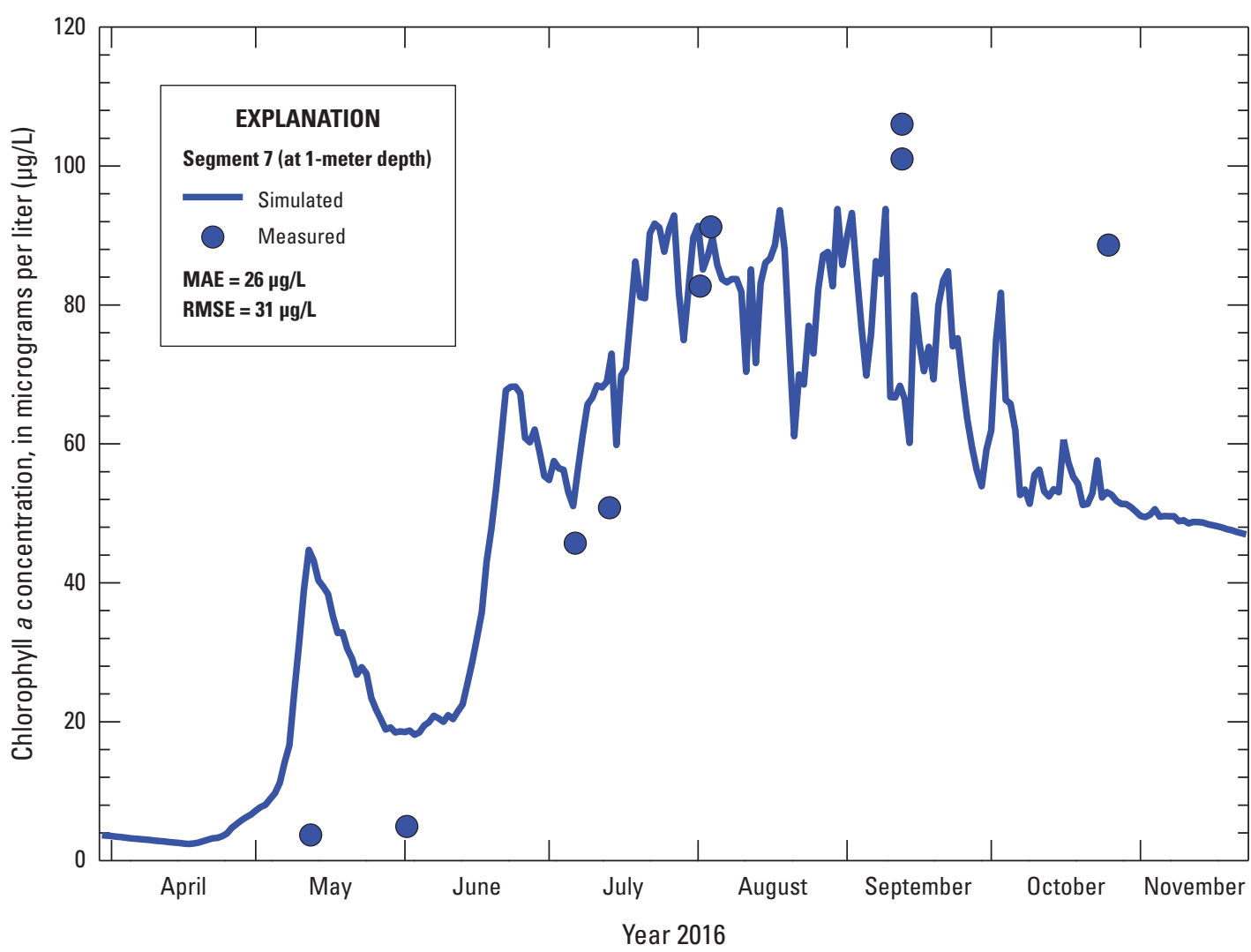

Figure 9. Simulated and measured chlorophyll a concentrations for the 1-meter depth at Madison Lake southwest deep point near Madison Lake, Minnesota (segment 7), March 30 to November 23, 2016.

\section{Nutrients}

Nutrients are controlled by many processes, such as inflow loads, algal production, and organic matter decay rates (Cole and Wells, 2015). One of the most important controls is the amount of nutrients (loads, determined in the model as concentration multiplied by streamflow and a unit conversion factor) contributed by the inflows. Madison Lake had a larger influx of nitrate earlier in 2014 with a larger influx of ammonia later in the year, whereas in 2016 for the model validation, the lake did not have the initial large influx of nitrate or the large midsummer influx of ammonia. Loading into lakes varies across ecoregions because of differences in soil fertility in the contributing drainage basin and land uses (for example, row-crop agriculture compared to deciduous forest).

Inlake processing of the nutrients is the major factor controlling nutrient concentrations, and a detailed discussion of the sources and sinks for Madison Lake is provided in Smith and others (2017). Madison Lake has fairly small flows from two inflows and seems to have considerably large groundwater sources relative to surface inflows. Agricultural land use is the dominant land use at about 50 percent for the drainage areas for Madison Lake with only 2 percent forest cover (Lindon and others, 2010), and the drainage basin to lake area ratio for Madison Lake is 4:1. Generally, basins with a smaller percentage of forest or other undeveloped land cover combined with a larger ratio of agricultural land use will have higher nutrient loads (U.S. Geological Survey, 1999).
As with water temperature and DO, new comparisons were warranted to make sure that the updated model adequately captured the nutrient dynamics for 2014 despite earlier calibration efforts (Smith and others, 2017). The focus for evaluating the model calibration and validation was three constituents of nitrogen and two constituents of phosphorus: nitrate plus nitrite, ammonia, total Kjeldahl nitrogen, orthophosphate, and total phosphorus. For the purposes of comparing simulated and measured concentrations, total Kjeldahl nitrogen was classified as the concentration of nitrogen present in ammonia, nitrate plus nitrite, and organically bound nitrogen (in living algal biomass and all organic matter pools). For the purposes of comparing simulated and measured concentrations, total phosphorus was classified as the concentration of phosphorus present in orthophosphate and bound up in organic matter (in living algal biomass and all organic matter pools). The primary tools for evaluating the goodness of fit for nutrients were the MAE and RMSE values (table 5), and all comparisons were for samples collected either from $1 \mathrm{~m}$ below the water surface or in the hypolimnion from the southwest deep point in Madison Lake (segment 7, fig. 1). However, these values could often be largely offset by only one or two measured samples because of the small number of total discrete samples (5 samples for 2014 and 4-10 samples for 2016, depending on the constituent).

Dissolved ammonia and dissolved nitrate plus nitrite distributions in Madison Lake were largely affected by the inflows and the lake hydrodynamics. Few differences between 
the simulated and measured dissolved ammonia concentrations were noted at the 1-m depth from July through September, for the calibration year (2014; fig. 10) and the validation year (2016; fig. 11). However, higher differences were observed when comparing simulated results to measured data for June and October 2014 samples, which were much higher than other samples. Overall, algal uptake of available ammonia was fairly rapid in simulations and measured samples for both years, with replenishment by organic matter decay and inflows. Algal uptake accounted for the lower dissolved ammonia concentrations during the middle of the simulation period for the simulated and measured values. The original 2014 MAE and RMSE values for dissolved ammonia, 0.18 and $0.31 \mathrm{mg} / \mathrm{L}$, respectively (Smith and others, 2017), were similar to the updated calibration (this report), with MAE and RMSE values of 0.17 and $0.33 \mathrm{mg} / \mathrm{L}$, respectively (fig. 10; table 5), for the new calibration. The 2016 validation closely matched the measured values, which were censored values because all the samples were at or below the method detection limit; the MAE and RMSE values for the 2016 validation were 0.01 and $0.02 \mathrm{mg} / \mathrm{L}$, respectively.

Simulated and measured dissolved nitrate plus nitrite concentrations are shown in figures 12 (2014) and 13 (2016) for the Madison Lake southwest deep point site. For nitrate, the two years were different: in 2014, nitrate started with a high initial value whereas 2016 started low. The model simulated both years with low MAE and RMSE values (table 5), including lower MAE and RMSE values with the updated 2014 calibration. For the original model (Smith and others, 2017), the nitrate MAE and RMSE values were 0.05 and $0.08 \mathrm{mg} / \mathrm{L}$, respectively, whereas the updated model MAE and RMSE values were 0.02 and 0.03 , respectively. The improvement likely was caused by an important change to the NO3S parameter that controls the nitrate sediment diffusion rate (Smith and others, 2017). Additionally, changes were made across the five algal groups to the algal stoichiometry and to the algal growth rates; all these changes would affect dissolved nitrate and nitrite concentrations.

Dissolved orthophosphate concentrations in the Madison Lake measured data were stable for both years (figs. 14 and 15) except for an unusually high measured value in October 2014. The simulated orthophosphate concentrations were considerably more variable because of the algal dynamics incorporated into the model and the cycling of nutrients through the various organic pools, algal communities, and the simulated macrophyte community of Madison Lake. At the end of the calibration (2014) and validation (2016) runs, a steady increase in simulated dissolved orthophosphate concentrations occurred primarily because of the lack of demand by the simulated algae and macrophytes. Overall, the MAE and RMSE values were 0.02 and $0.02 \mathrm{mg} / \mathrm{L}$, respectively, for both years (figs. 14 and 15; table 5).
Simulated and measured concentrations are shown for total Kjeldahl nitrogen in figures 16 and 17 for 2014 and 2016, respectively. The 2014 MAE and RMSE values for total Kjeldahl nitrogen were 0.35 and $0.43 \mathrm{mg} / \mathrm{L}$, respectively (fig. 16; table 5), slightly higher than the original calibration (Smith and others, 2017) of 0.29 and $0.33 \mathrm{mg} / \mathrm{L}$, respectively. The measured data indicate a dynamic range, from about 1.4 to $2.2 \mathrm{mg} / \mathrm{L}$. A peak in total Kjeldahl nitrogen for the simulated values occurred in late June because of the increase in ammonia and nitrate concentrations, with a steady increase from late July through mid-September caused by an accumulation in organic matter from the deterioration of algal biomass, macrophytes, and inflows. The simulated results generally followed the same pattern as the measured total Kjeldahl nitrogen concentrations, except for a steady decrease in total Kjeldahl nitrogen towards the end of the simulation period (fig. 16). For the 2016 validation, the model fit was improved over the 2014 calibration with MAE and RMSE values of 0.20 and $0.24 \mathrm{mg} / \mathrm{L}$, respectively. The simulated total nitrogen tracks the measured values throughout the simulation and includes the same late season decline. These decreases likely occurred because of the overall decay of the simulated organic matter pools and the decrease in simulated total algal biomass.

The CE-QUAL-W2 model also captured the wide range of total phosphorus across the vertical gradients at the southwest deep point, as shown for the epilimnion and hypolimnion depths (figs. 18 and 19), although the trends were better captured for the deeper hypolimnion. For the shallow depth in the epilimnion, the measured total phosphorus concentrations were stable but the simulated concentrations for the calibration (2014, fig. 18) and validation (2016, fig. 19) were too large. The model could have been fit to match the epilimnion concentrations better but would have sacrificed the hypolimnion phosphorus model fit with measured values and would have set phosphorus at unrealistically low stoichiometric equivalents for algal biomass and organic matter. In the hypolimnion, a steady and steep increase in the simulated total phosphorus occurred from late May until mid-September to greater than 1,200 micrograms per liter $(\mu \mathrm{g} / \mathrm{L})$, before crashing to the baseline of less than $150 \mu \mathrm{g} / \mathrm{L}$. These high values were confirmed for both years with the measured data, with a high value of $1,130 \mu \mathrm{g} / \mathrm{L}$ in 2014 and $815 \mu \mathrm{g} / \mathrm{L}$ in 2016 . The likely explanation for the large phosphorus concentrations in the simulated and measured values (figs. 18 and 19) was the large release rates in phosphorus from the lake sediments. The MAE values for the epilimnion (1-m depth) and hypolimnion (15.5- or 16.5-m depth) in 2016 were 52 and $65 \mu \mathrm{g} / \mathrm{L}$, respectively; the RMSE values for the epilimnion (1-m depth) and hypolimnion (16.5-m depth) were 53 and $70 \mu \mathrm{g} / \mathrm{L}$, respectively (fig. 18; table 5). The large drop in total phosphorus in late September through early October coincides with the turnover of Madison Lake and the mixing of all the lake water, which redistributed the concentrated total phosphorus to the lake volume. 


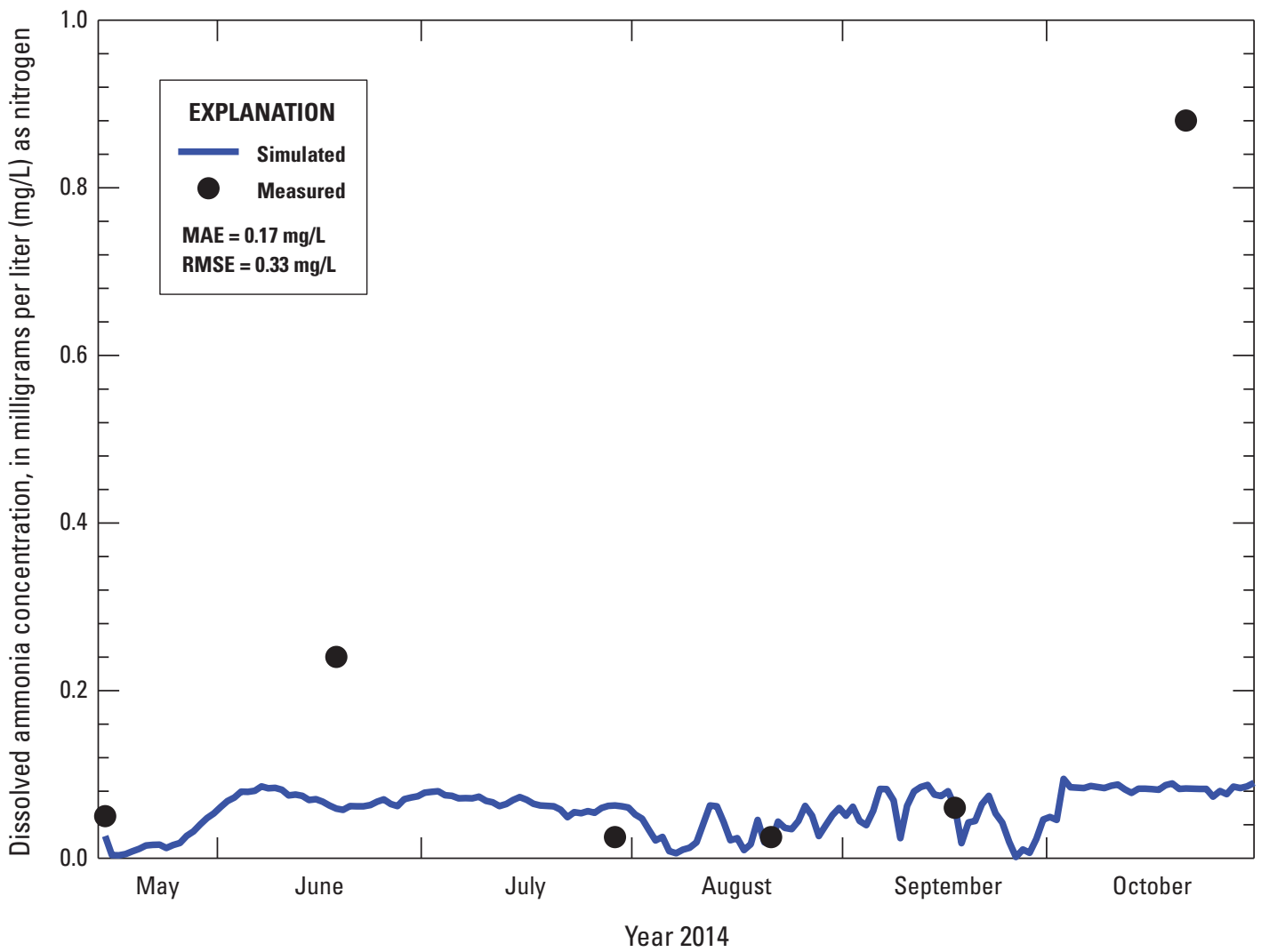

Figure 10. Simulated and measured dissolved ammonia concentrations at 1 meter below the water surface in model segment 7 containing the Madison Lake southwest deep point near Madison Lake, Minnesota, May 15 to November 1, 2014, with values of mean absolute error (MAE) and root mean square error (RMSE).

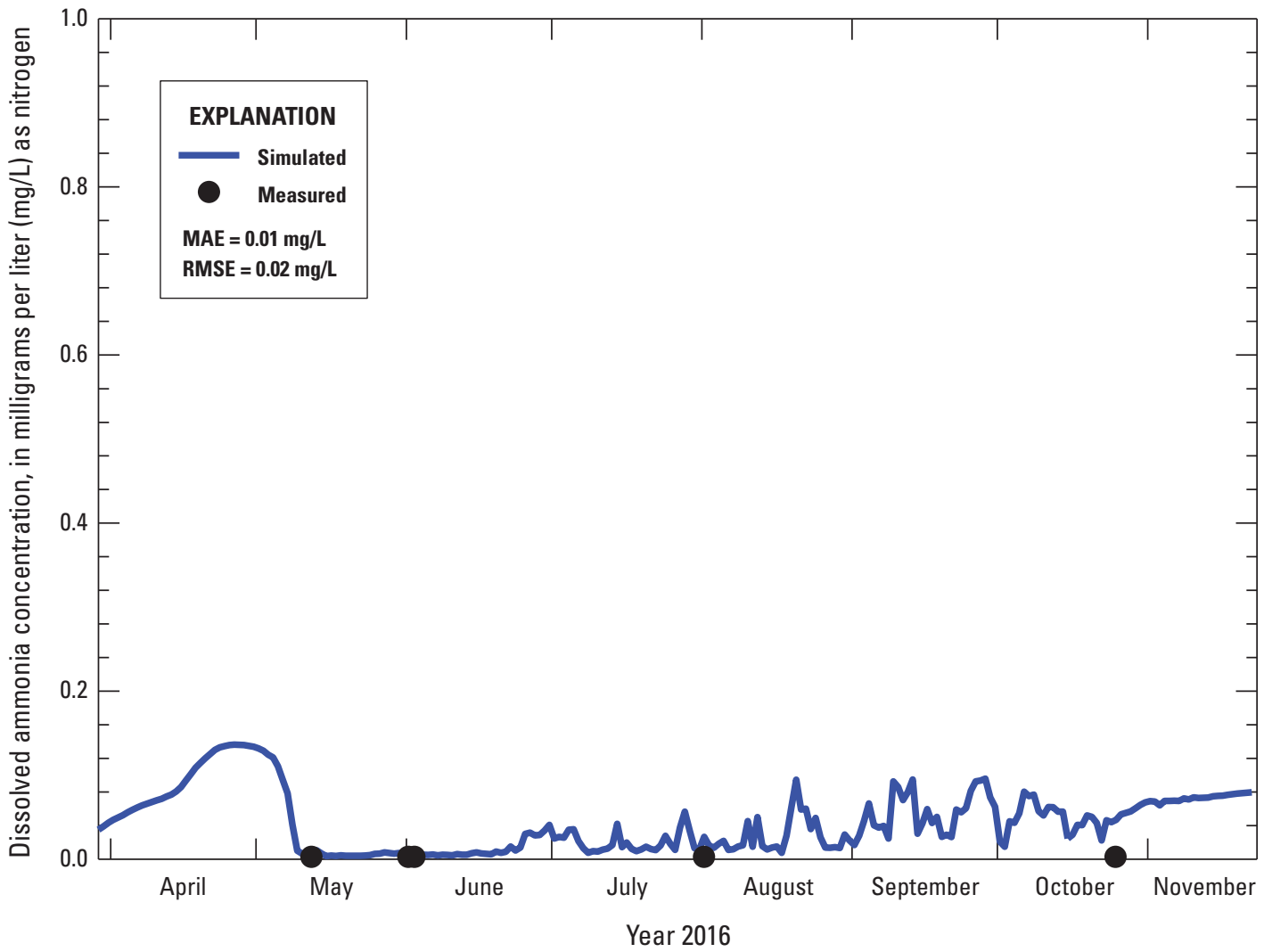

Figure 11. Simulated and measured dissolved ammonia concentrations at 1 meter below the water surface in model segment 7 containing the Madison Lake southwest deep point near Madison Lake, Minnesota, March 30 to November 23, 2016, with values of mean absolute error (MAE) and root mean square error (RMSE). 

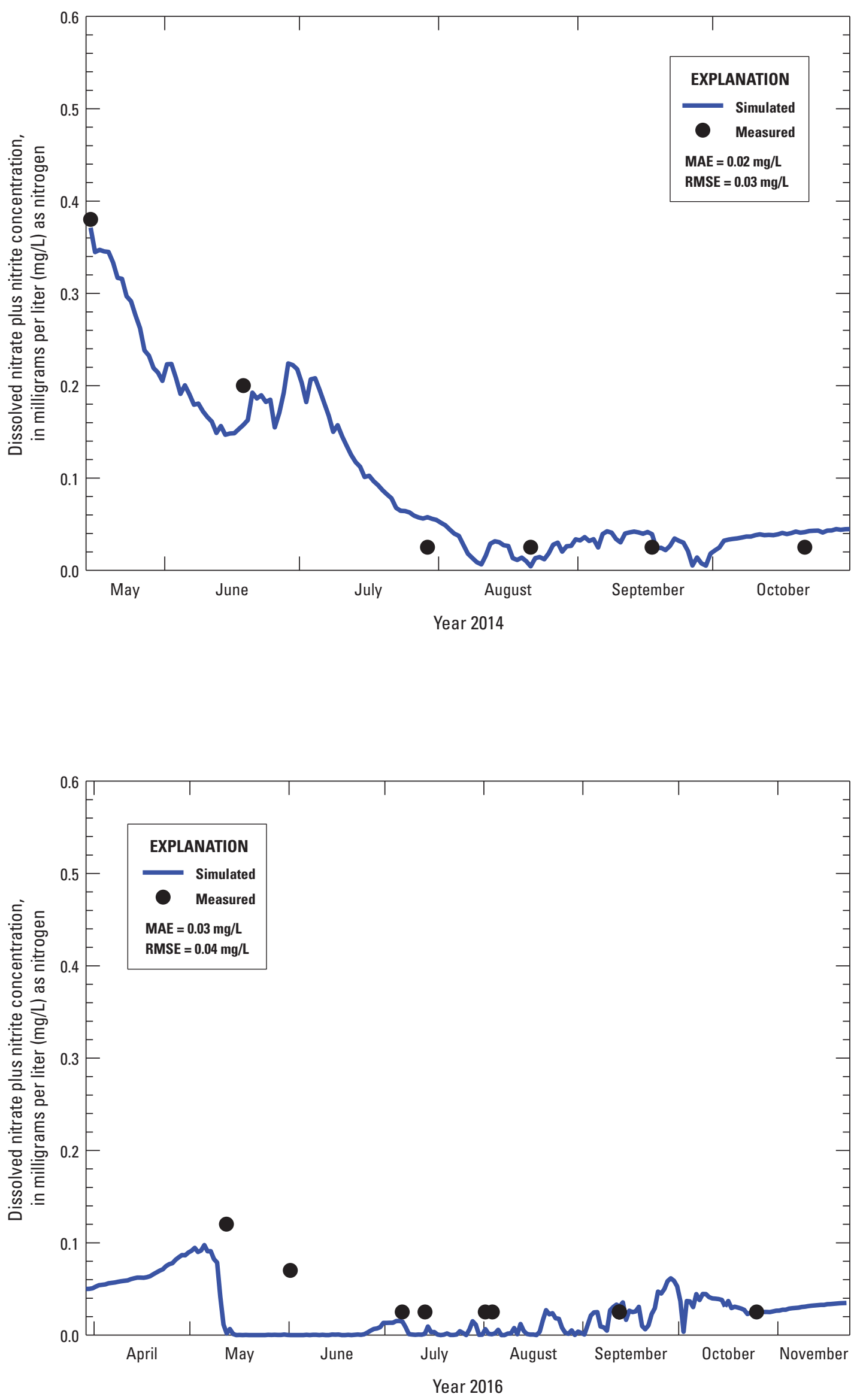

Figure 12. Simulated and measured dissolved nitrate plus nitrite concentrations at 1 meter below the water surface in model segment 7 containing the Madison Lake southwest deep point near Madison Lake, Minnesota, May 15 to November 1, 2014, with values of mean absolute error (MAE) and root mean square error (RMSE).
Figure 13. Simulated and measured dissolved nitrate plus nitrite concentrations at 1 meter below the water surface in model segment 7 containing the Madison Lake southwest deep point near Madison Lake, Minnesota, March 30 to November 23, 2016, with values of mean absolute error (MAE) and root mean square error (RMSE). 

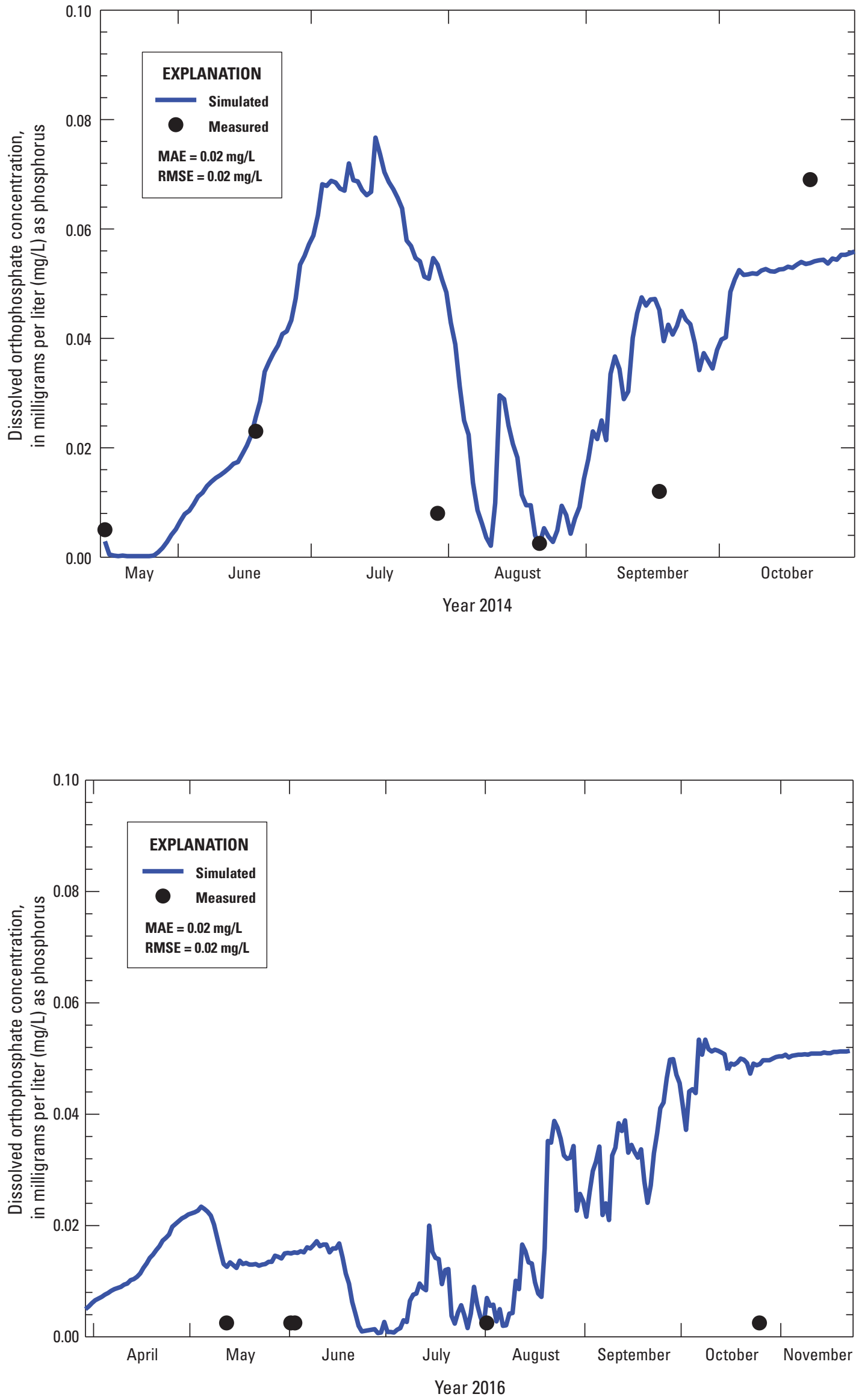

Figure 14. Simulated and measured dissolved orthophosphate concentrations at 1 meter below the water surface in model segment 7 containing the Madison Lake southwest deep point near Madison Lake, Minnesota, May 15 to November 1, 2014, with values of mean absolute error (MAE) and root mean square error (RMSE).
Figure 15. Simulated and measured dissolved orthophosphate concentrations at 1 meter below the water surface in model segment 7 containing the Madison Lake southwest deep point near Madison Lake, Minnesota, March 30 to November 23, 2016, with values of mean absolute error (MAE) and root mean square error (RMSE). 

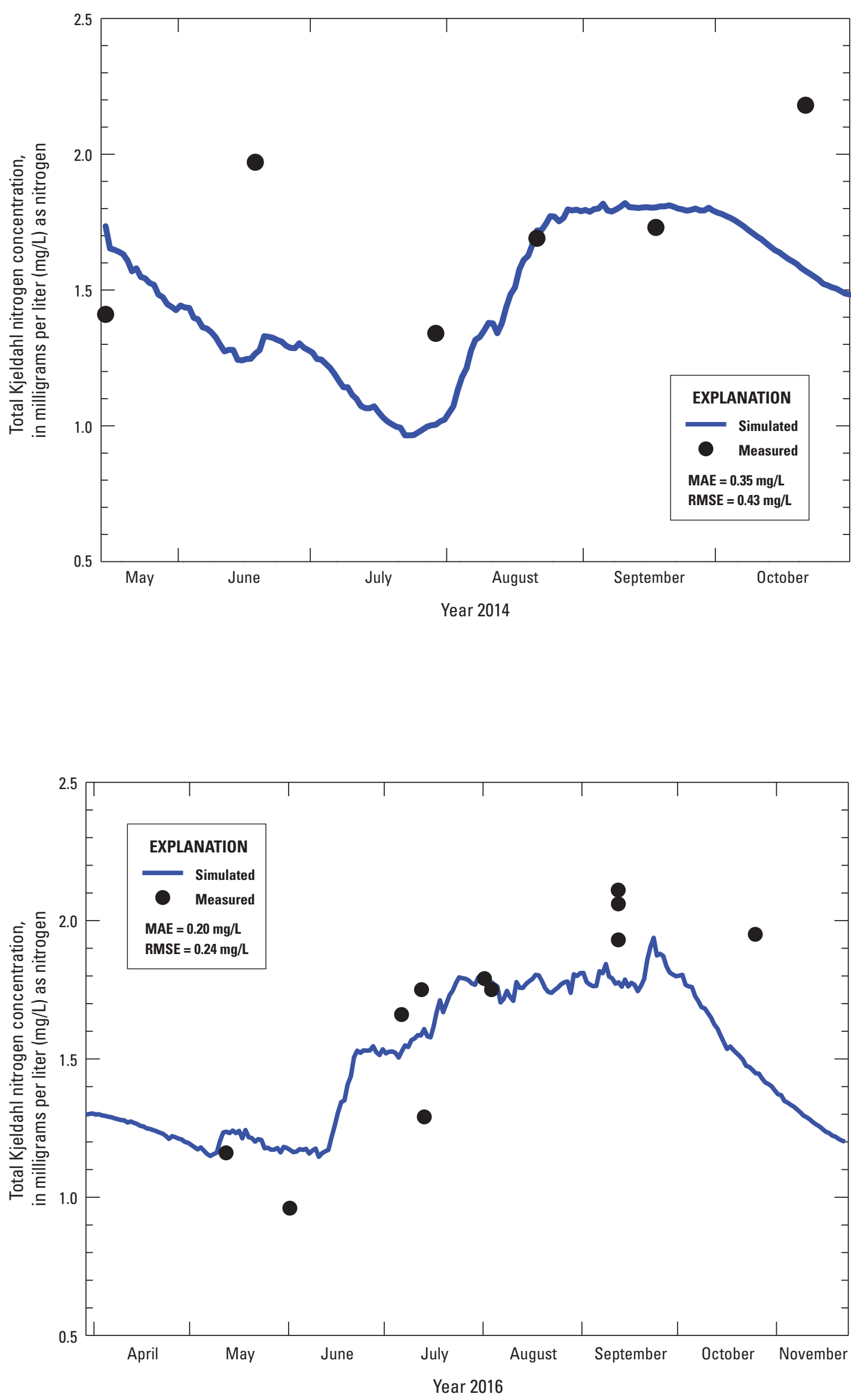

Figure 16. Simulated and measured total Kjeldahl nitrogen concentrations at 1 meter below the water surface in model segment 7 containing the Madison Lake southwest deep point near Madison Lake, Minnesota, May 15 to November 1, 2014, with values of mean absolute error (MAE) and root mean square error (RMSE).
Figure 17. Simulated and measured total Kjeldahl nitrogen concentrations at 1 meter below the water surface in model segment 7 containing the Madison Lake southwest deep point near Madison Lake, Minnesota, March 30 to November 23, 2016, with values of mean absolute error (MAE) and root mean square error (RMSE). 


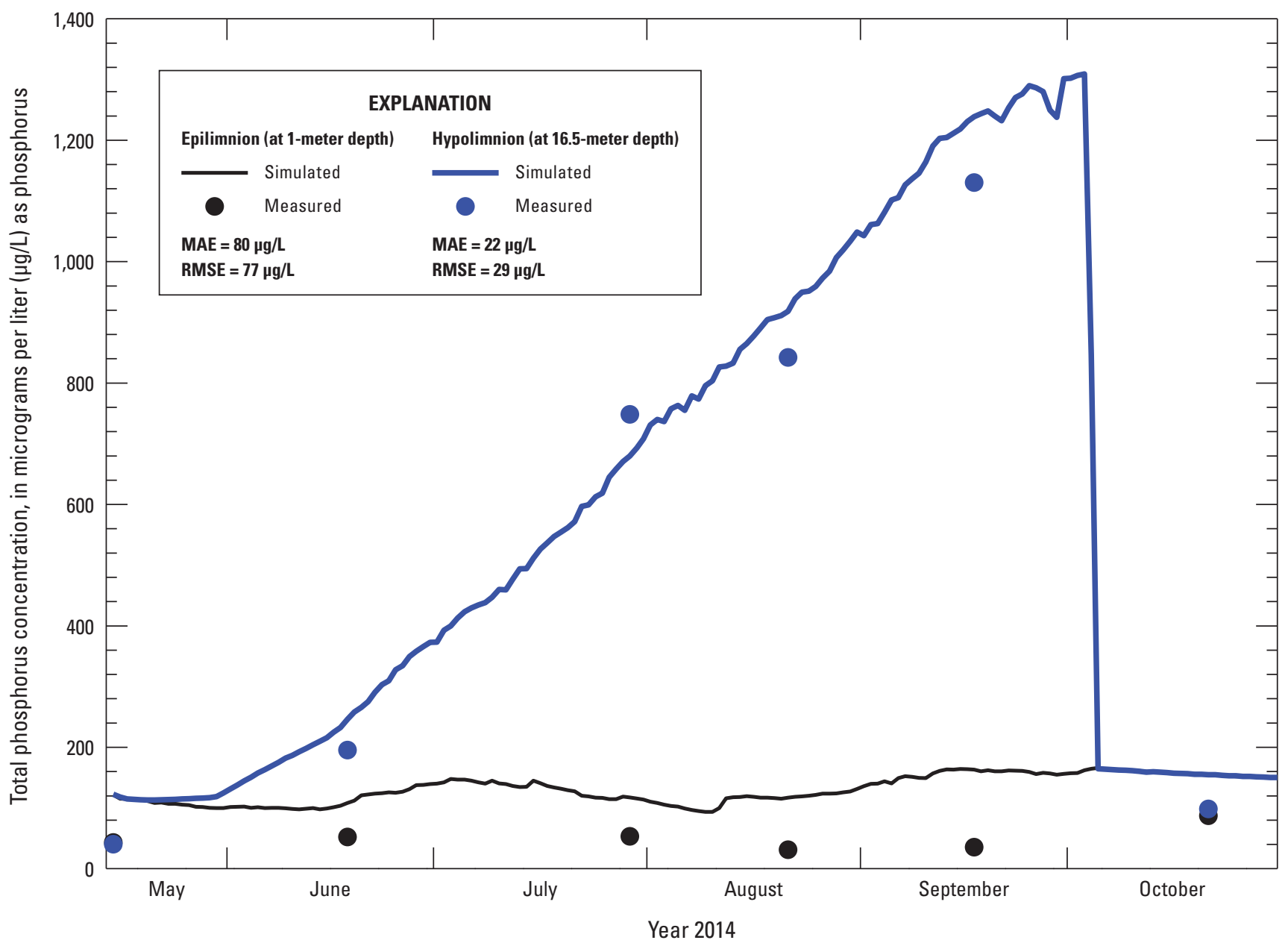

Figure 18. Simulated and measured total phosphorus concentrations at 1 meter and 16.5 meters below the water surface in model segment 7 containing the Madison Lake southwest deep point near Madison Lake, Minnesota, May 15 to November 1, 2014, with values of mean absolute error (MAE) and root mean square error (RMSE).

\section{Phosphorus Loads}

Monthly total phosphorus budgets were calculated for the updated Madison Lake model for 2014 and 2016 (table 6). Budgets included phosphorus subdivisions of external phosphorus load derived from organic matter, external phosphorus load derived from orthophosphate, and internal phosphorus load released by zero-order sediment release. Additionally, monthly phosphorus budgets were calculated for the original Madison Lake model (Smith and others, 2017) and two sensitivity analyses completed in the same report, both with a 20-percent variation in the incoming dissolved orthophosphate load (plus or minus 20-percent increase). Phosphorus budgets included external sources from the two tributaries, the distributed tributary flow (unaccounted surface flow, groundwater flow), and internal phosphorus loading from sediment release. Negative numbers in the table denote a loss term caused by net export of phosphorus for the distributed tributary flow.
The 2016 model validation had a higher overall total phosphorus budget than the 2014 model calibration. Even only considering the periods of overlap (May through October), 2016 had about 25 percent more total phosphorus loading than 2014. More precipitation occurred in 2016 compared to 2014 and was a potential driver of the increased loads given the available concentration data for the two years were similar (Smith, 2019). When comparing the monthly data, the highest 2014 phosphorus loads occurred in June $(2,750$ kilograms $[\mathrm{kg}])$ before dropping throughout the rest of the summer (fig. 20), whereas the 2016 monthly phosphorus loads stayed high from June to October (ranging from 855.9 to 1,783 kilograms per month). Most of the phosphorus load for the remainder of 2014 after August likely came from internal loading because there was little to no flow into Madison Lake after early September. 


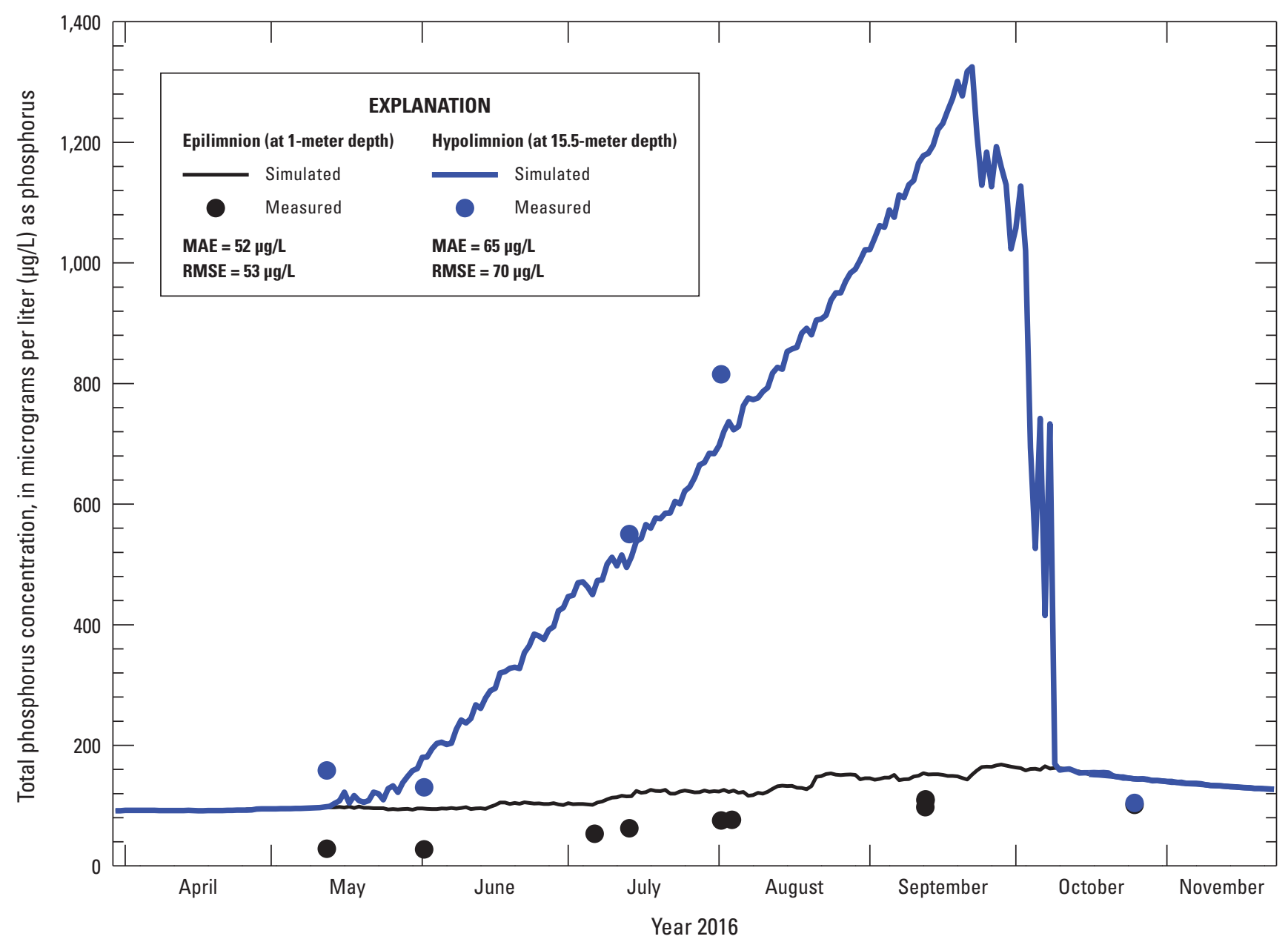

Figure 19. Simulated and measured total phosphorus concentrations at 1 meter and 15.5 meters below the water surface in model segment 7 containing the Madison Lake southwest deep point near Madison Lake, Minnesota, March 30 to November 23, 2016, with values of mean absolute error (MAE) and root mean square error (RMSE).

For the other three model runs (scenarios 3-5 in table 6), the original 2014 model was included to demonstrate that there was little difference in the phosphorus budget between the original and updated model. In the sensitivity analysis, increasing the external dissolved orthophosphate load by 20 percent (scenario 4 in table 6) compared to the original model (scenario 3 in table 6) increased the overall phosphorous load by about 7 percent $(5,596 \mathrm{~kg}$ versus 5,244 kg). Alternatively, decreasing the external dissolved orthophosphate load by 20 percent (scenario 5 in table 6) compared to the original model (scenario 3 in table 6 ) decreased the total phosphorus load by about 7 percent $(4,904 \mathrm{~kg}$ versus $5,244 \mathrm{~kg})$.
The internal sediment release of phosphorus accounted for 39.0-48.1 percent of the total overall load for each model run (table 6). On a monthly basis, the internal load covers a much wider range, ranging from almost no internal sediment release of phosphorus to dominating the overall monthly load. The high percentage of internal load is particularly high in the summer months when hypoxic conditions dominated the lake's hypolimnion, with low release rates occurring before hypoxia dominates the lake or after the fall lake mixing. Little difference existed between the total internal load for 2014 and 2016 (scenarios 1-2 in table 6), relative to the large differences in external loads observed between 2014 and 2016. 


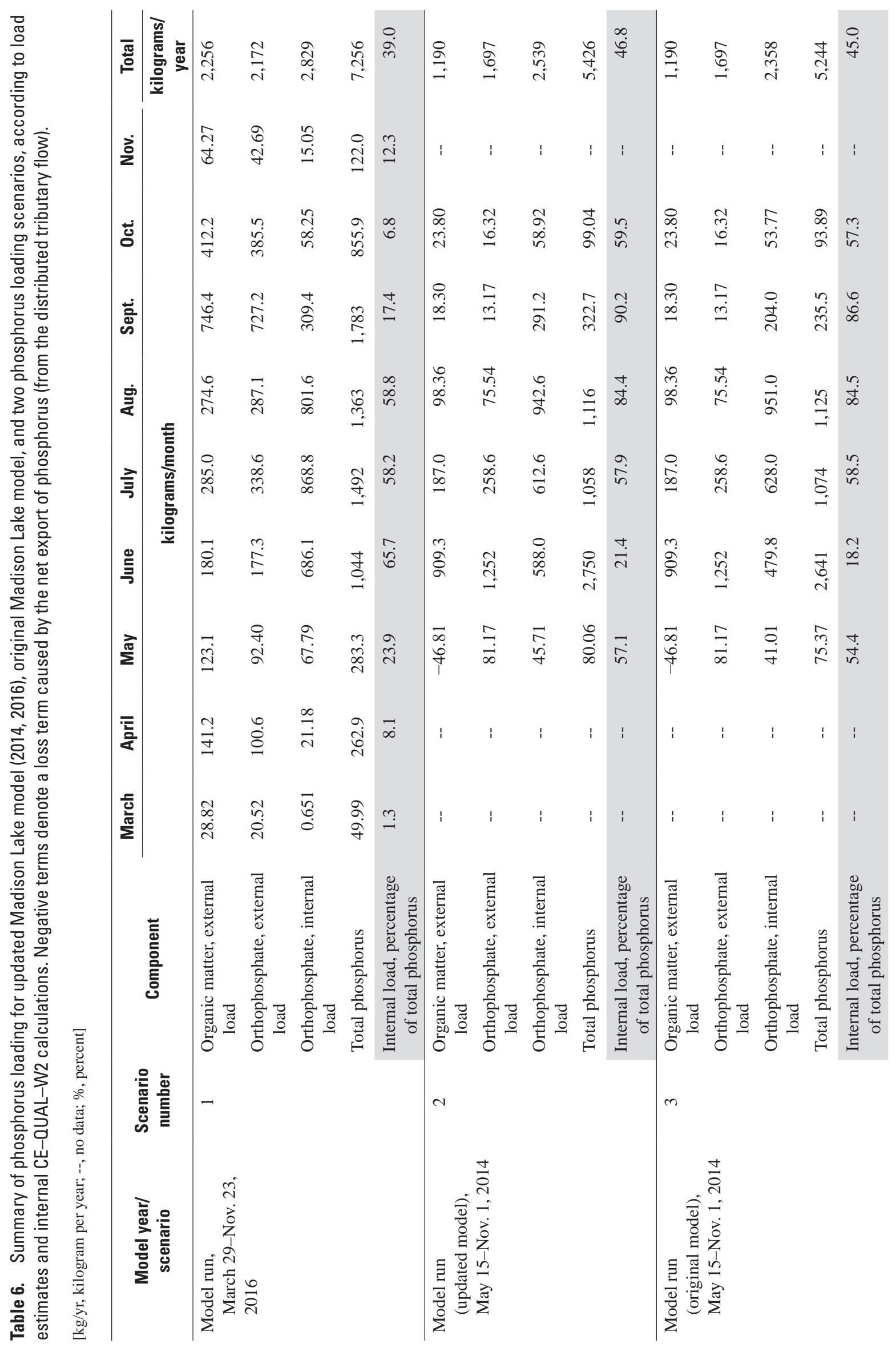




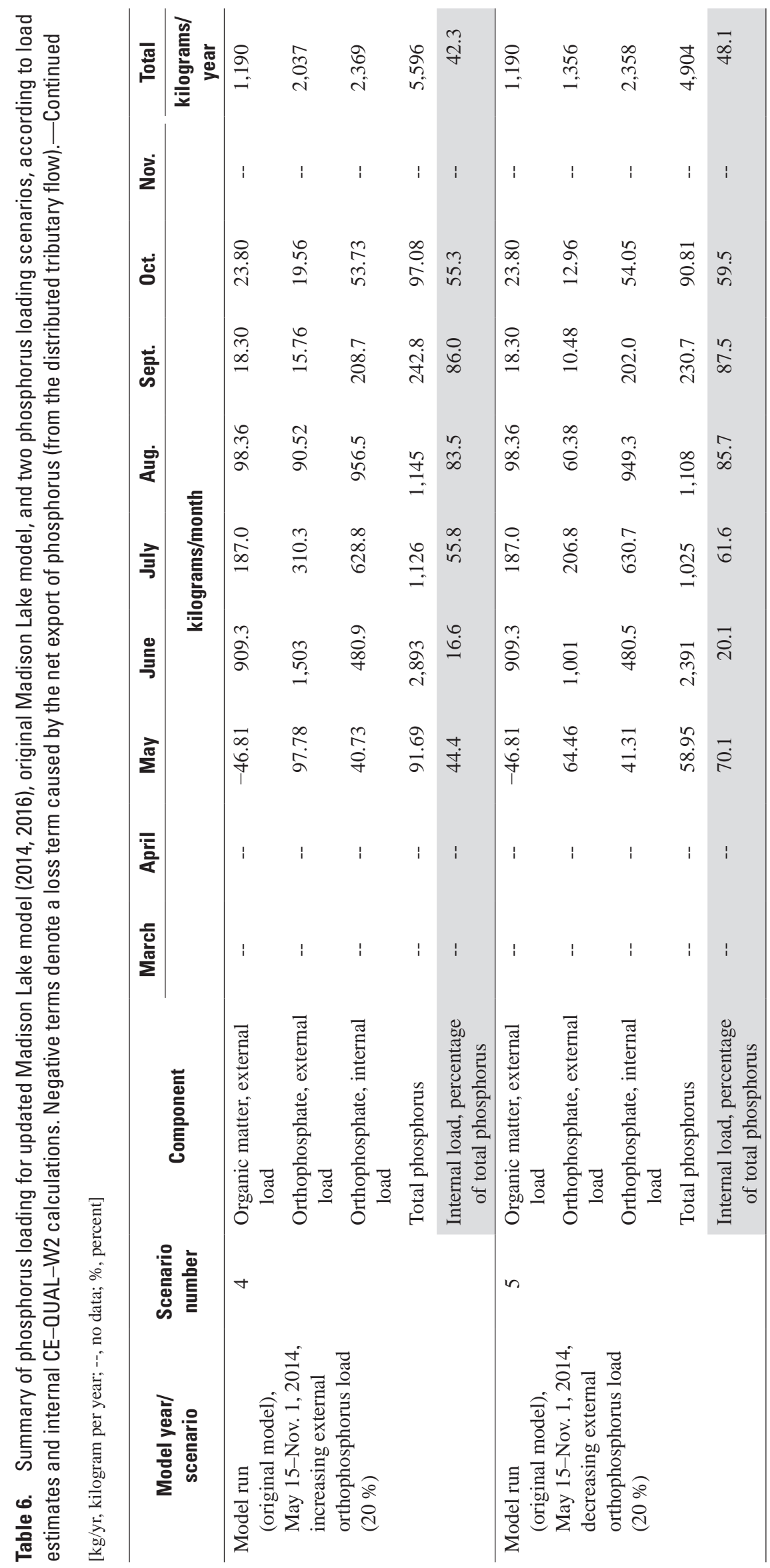




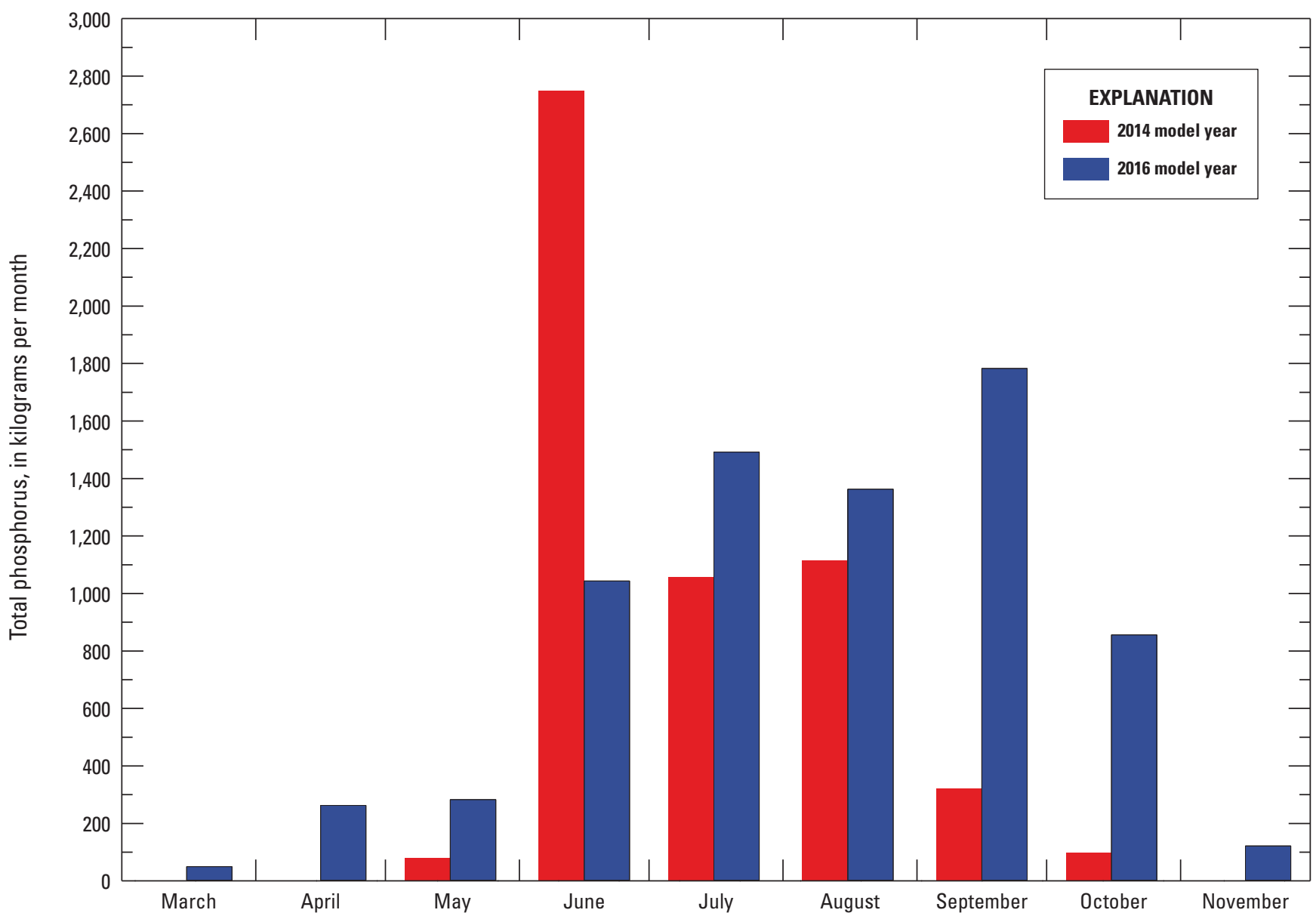

Figure 20. Total monthly phosphorus loads, in kilograms per month, for the 2014 and 2016 model years for the updated model.

\section{Model Limitations}

A full understanding of model limitations is necessary to better evaluate the performance of any water-quality model. The previous Madison Lake CE-QUAL-W2 model report provided a detailed summary of these limitations, but some limitations are reiterated here because of the limited datasets available for Madison Lake. The fixed number of waterquality samples used to calibrate the model may not have captured the full range of conditions in the dynamic systems. Also, all boundary condition datasets had limitations. Waterquality data were linearly interpolated between sampling dates. The continuous streamflows for both tributaries and one outflow location, based on applying the 2014 elevationstreamflow ratings (appendix table 1-1 in Smith and others [2017]) to continuous water levels, were unavailable for 2016. Instead, 2014 elevation-streamflow ratings (Smith and others, 2017) were applied to the daily water-surface elevation for the lake. Inherent errors in this approach would be captured by the constructed distributed tributary flows, but this still represents an important limitation. Finally, continuous water temperature data were also unavailable for 2016. Water temperatures were estimated using a regression relation between air and water temperature that was developed from data collected in 2014.

The lack of specific information on algal growth rates, mortality rates, sinking rates, and algal light saturation coefficients also put limitations on the model; furthermore, the full stoichiometric equivalences for the individual algal groups were not known for the Madison Lake phytoplankton. Incubation experiments on some of these algal parameters could help constrain model parameterization, rather than depending on a manual parameter estimation process. Literature values for these constants do exist, but they tend to demonstrate a wide range that only helps constrain the parameter estimation process rather than fix the parameters to a single value. Overall, the model did demonstrate the ability to simulate the different algal groups throughout the year, but better characterization of the algal community dynamics from either field or laboratory experimentation would improve the model further.

Finally, it is possible that the buoyant Cyanophyta group does not only float on the surface of the lake but also moves vertically within the water column. The current 
parameterization controls the buoyancy with a settling rate of 0 and would not account for vertical migration. At this time (2019), the current version of CE-QUAL-W2 is not capable of capturing vertical algal migration.

\section{Summary}

A previously developed CE-QUAL-W2 model for Madison Lake, Minnesota, simulated the algal community dynamics, water quality, and fish habitat suitability of Madison Lake under recent (2014) meteorological conditions. This previously developed model simulated the complex interplay between external nutrient loading, internal nutrient loading from sediment release of phosphorus, and the organic matter decomposition of the algal biomass. However, the partitioning of Cyanophyta within the modeling framework was simplified to one group and did not account for differences in how Cyanophyta populations are affected by light conditions, the use of nitrogen, temperature growth ranges, and differences in settling rates. Properly capturing Cyanophyta dynamics is important given the potential risks posed by potential large algal blooms. For example, when Cyanophyta form large blooms, recreational activities can become restricted in certain areas because of thick algal scums or algal mats, in addition to the possible production of a class of toxins known as cyanotoxins capable of threatening human health, domestic animals, and wildlife. Therefore, we updated the model to partition the Cyanophyta into a group that fixed nitrogen and a second, more buoyant Cyanophyta group that did not independently fix nitrogen.

The U.S. Geological Survey, in cooperation with the St. Croix Watershed Research Station (Science Museum of Minnesota) with support from the Environmental and Natural Resources Trust Fund of Minnesota (Legislative-Citizen Commission on Minnesota Resources), updated the Madison Lake CE-QUAL-W2 model to address the shortcomings of simulating Cyanophyta in the previously developed model and better characterize Cyanophyta into two groups. In addition to updating the Cyanophyta group differentiation, the part of the model that handles the simulation of algal community dynamics was updated while preserving model predictive capabilities for nutrients, water temperature, and dissolved oxygen (DO). The calibration and validation of the updated model were completed using recent meteorological conditions with large and persistent Cyanophyta blooms (2014 and 2016). Overall, the model simulations predicted the persistently large total phosphorus concentrations in the hypolimnion of Madison Lake, key differences in nutrient concentrations between 2014 and 2016, and Cyanophyta bloom persistence.

For calibration targets, the CE-QUAL-W2 model successfully predicted water temperature based on the two metrics of mean absolute error and root mean square error. One of the main calibration tools for CE-QUAL-W2 model development was the vertical profile temperature data. Altogether, simulated Madison Lake water temperatures tracked measured water temperatures throughout the water column. In addition to water temperature, the CE-QUAL-W2 model successfully predicted DO concentration based on the same two metrics of mean absolute error and root mean square error. Along with temperature, DO is a key metric to illustrate the accuracy of the model's calibration. Simulated vertical profiles of DO concentration generally matched the largest change in measured DO concentration, including the approximate depth, slope, and timing of large shifts.

Monthly total phosphorus budgets calculated for the updated Madison Lake model for 2014 and 2016 indicated that 2016 had substantially more internal and external phosphorus loading. Most of the additional phosphorus loading was from external inputs into Madison Lake rather than internal phosphorus release from sediments. The additional loading was likely from increased precipitation, and therefore higher flows, for 2016 because little to no inflow flowed into Madison Lake after September 2014. As a percentage of the overall load, the internal sediment release of phosphorus accounted for between 39 and 48.1 percent of the total external and internal phosphorus loads.

\section{References Cited}

American Water Works Association, American Public Works Association, and Water Environment Federation, 1997a, 4500-P phosphorus, in Rice, E.W., Baird, R.B., Eaton, A.D., and Clesceri, L.S., eds., Standard methods for the examination of water and wastewater (20th ed.): New York, American Water Works Association, American Public Works Association, and Water Environment Federation, p. 4-108-4-117.

American Water Works Association, American Public Works Association, and Water Environment Federation, 1997b, 10200-H chlorophyll, in Rice, E.W., Baird, R.B., Eaton, A.D., and Clesceri, L.S., eds., Standard methods for the examination of water and wastewater (20th ed.): New York, American Water Works Association, American Public Works Association, and Water Environment Federation, p. 10-18-10-25.

American Water Works Association, American Public Works Association, and Water Environment Federation, 1997c, SM 2540C-Total dissolved solids dried at $180^{\circ} \mathrm{C}$, in Rice, E.W., Baird, R.B., Eaton, A.D., and Clesceri, L.S., eds., Standard methods for the examination of water and wastewater (20th ed.): New York, American Water Works Association, American Public Works Association, and Water Environment Federation, p. 2-57. 
American Water Works Association, American Public Works Association, and Water Environment Federation, 1997d, 4500- $\mathrm{SiO}_{2}$ C. molybdosilicate method, in Rice, E.W., Baird, R.B., Eaton, A.D., and Clesceri, L.S., eds., Standard methods for the examination of water and wastewater (20th ed.): New York, American Water Works Association, American Public Works Association, and Water Environment Federation, p. 4-156-4-158.

Anderson, P., and Martin, I., 2015, Standard operating procedures (SOP)_Lake water quality sampling: St. Paul, Minn., Minnesota Pollution Control Agency, 17 p.

Bales, J.D., and Robbins, J.C., 1999, A dynamic waterquality modeling framework for the Neuse River Estuary, North Carolina: U.S. Geological Survey Water-Resources Investigations Report 99-4017, 42 p. [Also available at https://pubs.usgs.gov/wri/1999/4017/report.pdf.]

Cole, T.M., and Wells, S.A., 2015, CE-QUAL-W2-A two-dimensional, laterally averaged, hydrodynamic and water quality model, version 4.0: Portland State University Report, 847 p.

Fang, X., Stefan, H.G., and Alam, S.R., 1999, Simulation and validation of fish thermal DO habitat in north-central US lakes under different climate scenarios: Ecological Modelling, v. 118, no. 2-3, p. 167-191. [Also available at https://doi.org/10.1016/S0304-3800(99)00018-6.]

Flowers, J.D., Hauck, L.M., and Kiesling, R.L., 2001, USDA Lake Waco-Bosque River Initiative-Water quality modeling of Lake Waco using CE-QUAL-W2 for assessment of phosphorus control strategies: Stephenville, Tex., Texas Institute for Applied Environmental Research TR0114, 73 p.

Galloway, J.M., and Green, W.R., 2006, Application of a twodimensional reservoir water-quality model of Beaver Lake, Arkansas, for the evaluation of simulated changes in input water quality, 2001-2003: U.S. Geological Survey Scientific Investigations Report 2006-5302, 31 p. [Also available at https://pubs.usgs.gov/sir/2006/5302/.]

Galloway, J.M., Ortiz, R.F., Bales, J.D., and Mau, D.P., 2008, Simulation of hydrodynamics and water quality in Pueblo Reservoir, southeastern Colorado, for 1985 through 1987 and 1999 through 2002: U.S. Geological Survey Scientific Investigations Report 2008-5056, 56 p. [Also available at https://pubs.usgs.gov/sir/2008/5056/.]

Graham, J.L., Dubrovsky, N.M., and Eberts, S.M., 2016, Cyanobacterial harmful algal blooms and U.S. Geological Survey science capabilities (ver. 1.1, December 2017): U.S. Geological Survey Open-File Report 2016-1174, 12 p. [Also available at https://doi.org/10.3133/ofr20161174.]
Green, W.R., Galloway, J.M., Richards, J.M., and Wesolowski, E.A., 2003, Simulation of hydrodynamics, temperature, and dissolved oxygen in Table Rock Lake, Missouri, 1996-1997: U.S. Geological Survey Water-Resources Investigations Report 2003-4237, 35 p. [Also available at https://doi.org/10.3133/wri034237.]

Lindenberg, M.K., Hoilman, G., and Wood, T.M., 2008, Water quality conditions in Upper Klamath and Agency Lakes, Oregon, 2006: U.S. Geological Survey Scientific Investigations Report 2008-5201, 66 p. [Also available at https://pubs.usgs.gov/sir/2008/5201/.]

Lindon, M., and Heiskary, S.A., 2007, Microcystin levels in eutrophic south central Minnesota lakes: Minnesota Lake Water Quality Assessment Series wq-lar3-11, 53 p. [Also available at https:/www.pca.state.mn.us/sites/default/files/ wq-lar3-11.pdf.]

Lindon, M., and Heiskary, S., 2009, Blue-green algal toxin (microcystin) levels in Minnesota lakes: Lake and Reservoir Management, v. 25, no. 3, p. 240-252. [Also available at https://doi.org/10.1080/07438140903032424.]

Lindon, M., Valley, R., and Mackenthun, S., 2010, Sentinel Lake Assessment Report-Madison Lake (07-0044), Blue Earth County, Minnesota: St. Paul, Minn., Minnesota Pollution Control Agency, 43 p., accessed May 11, 2016, at https://www.pca.state.mn.us/sites/default/files/ wq-2slice07-0044.pdf.

Loftin, K.A., Graham, J.L., Hilborn, E.D., Lehmann, S.C., Meyer, M.T., Dietze, J.E., and Griffith, C.B., 2016, Cyanotoxins in inland lakes of the United States-Occurrence and potential recreational health risks in the EPA National Lakes Assessment 2007: Harmful Algae, v. 56, p. 77-90. [Also available at https://doi.org/10.1016/j.hal.2016.04.001.]

Maier, R.J., 2004, Nitrogen fixation and respiration-Two processes linked by the energetic demands of nitrogenase, chap. 5 of Zannoni, D., ed., Respiration in archaea and bacteria-Advances in photosynthesis and respiration: Dordrecht, Netherlands, Springer Publishing, p. 101-120. [Also available at https://doi.org/10.1007/978-1-4020-3163-2_5.]

Merel, S., Walker, D., Chicana, R., Snyder, S., Baurès, E., and Thomas, O., 2013, State of knowledge and concerns on cyanobacterial blooms and cyanotoxins: Environment International, v. 59, p. 303-327. [Also available at https://doi.org/10.1016/j.envint.2013.06.013.]

Minnesota Department of Health, 2016, Environmental laboratory sampling and analysis guide: St. Paul, Minn., Minnesota Department of Health, 57 p., accessed May 11, 2016, at https://mn.mdh.mastercontrol.com/mastercontrol/ Main/MASTERControl/vault/view_doc.cfm?ls_ $\mathrm{id}=3$ Y6QYIKDRJFCLJ7N7L. 
Minnesota Department of Natural Resources, 2016a, Fisheries lake survey-Madison Lake: Minnesota Department of Natural Resources web page, accessed May 11, 2016, at https://www.dnr.state.mn.us/lakefind/showreport. html? downum $=07004400$.

Minnesota Department of Natural Resources, 2016b, Lake bathymetric outlines, contours, vegetation, and DEM: Minnesota Department of Natural Resources web page, accessed May 11, 2016, at https://gisdata.mn.gov/dataset/ water-lake-bathymetry.

Minnesota Department of Natural Resources, 2019a, Lake Level Minnesota volunteering: Minnesota Department of Natural Resources web page, accessed June 21, 2019, at https://www.dnr.state.mn.us/climate/waterlevels/lakes/ volunteering.html.

Minnesota Department of Natural Resources, 2019b, Lake name-Madison, water level data: Minnesota Department of Natural Resources web page, accessed May 25, 2019, at https://www.dnr.state.mn.us/lakefind/showlevel. html?downum $=07004400$.

Minnesota Pollution Control Agency, 2018, Surface water data-Lake and stream water quality assessment information [Madison: At Madison Lake (Town) (Lake)]: Minnesota Pollution Control Agency web page, accessed June 21, 2019, at https://cf.pca.state.mn.us/water/watershedweb/ wdip/waterunit.cfm?wid=07-0044-00.

National Centers for Environmental Information, 2016, 1981-2010 station normals of temperature, precipitation, and heating and cooling degree days (Mankato, MN, USA, GHCND: USC00215073): National Oceanic and Atmospheric Administration, 4 p.

National Climatic Data Center, 2016, Climate data online: National Oceanic and Atmospheric Administration digital data, accessed May 11, 2016, at https://www.ncdc.noaa.gov/ cdo-web/.

National Climatic Data Center, 2018, Climate data online: National Oceanic and Atmospheric Administration digital data, accessed August 25, 2018, at https://www.ncdc.noaa.gov/cdo-web/.

O’Neil, J.M., Davis, T.W., Burford, M.A., and Gobler, C.J., 2012, The rise of harmful cyanobacterial blooms - The potential roles of eutrophication and climate change: Harmful Algae, v. 14, p. 313-334. [Also available at https://doi.org/10.1016/j.hal.2011.10.027.]
Paerl, H.W., and Otten, T.G., 2013, Harmful cyanobacterial blooms - Causes, consequences, and controls: Microbial Ecology, v. 65, no. 4, p. 995-1010. [Also available at https://doi.org/10.1007/s00248-012-0159-y.]

PhycoTech, 2019, General technical approach (ASA): St. Joseph, Mich., PhycoTech, Inc., 17 p. [Also available at https://www.phycotech.com/Portals/0/PDFs/GenTech.pdf.]

Preud'homme, E.B., and Stefan, H.G., 1992, Relationship between water temperatures and air temperatures for central U.S. streams: University of Minnesota, St. Anthony Falls Hydraulic Laboratory Project Report No. 333, 143 p. [Also available at http://hdl.handle.net/11299/108663.]

Rantz, S.E., and others, 1982a, Measurement and computation of streamflow-Volume 1-Measurement of stage and discharge: U.S. Geological Survey Water-Supply Paper 2175,313 p. [Also available at https://pubs.usgs.gov/wsp/ wsp2175/.]

Rantz, S.E., and others, 1982b, Measurement and computation of streamflow-Volume 2-Computation of discharge: U.S. Geological Survey Water-Supply Paper 2175, 373 p. [Also available from https://pubs.usgs.gov/wsp/wsp2175/.]

Sigee, D.C., 2005, Freshwater microbiology-Biodiversity and dynamic interactions of microorganisms in the aquatic environment: West Sussex, England, John Wiley and Sons, Ltd., 524 p.

Smith, E.A., 2019, Updated CE-QUAL-W2 waterquality model for Madison Lake, Minnesota, 2014 and 2016: U.S. Geological Survey data release, https://doi.org/10.5066/P92YEVPO.

Smith, E.A., Kiesling, R.L., Galloway, J.M., and Ziegeweid, J.R., 2014, Water quality and algal community dynamics of three sentinel deepwater lakes in Minnesota utilizing CE-QUAL-W2 models: U.S. Geological Survey Scientific Investigations Report 2014-5066, 73 p., accessed August 29, 2019, at https://doi.org/10.3133/sir20145066.]

Smith, E.A., Kiesling, R.L., and Ziegeweid, J.R., 2017, Water-quality models to assess algal community dynamics, water quality, and fish habitat suitability for two agricultural land-use dominated lakes in Minnesota, 2014: U.S. Geological Survey Scientific Investigations Report 2017-5056, 65 p., accessed August 29, 2019, at https://doi.org/10.3133/ sir20175056. 
Smith, E.A., Kiesling, R.L., Ziegeweid, J.R., Elliott, S.M., and Magdalene, S., 2018, Simulation of hydrodynamics, water quality, and lake sturgeon habitat volumes in Lake St. Croix, Wisconsin and Minnesota, 2013: U.S. Geological Survey Scientific Investigations Report 2017-5157, 60 p., accessed August 29, 2019, at https://doi.org/10.3133/ sir20175157.

Sullivan, A.B., and Rounds, S.A., 2004, Modeling hydrodynamics, temperature, and water quality in Henry Hagg Lake, Oregon, 2000-03: U.S. Geological Survey Scientific Investigations Report 2004-5261, 38 p. [Also available at https://pubs.usgs.gov/sir/2004/5261/.]

Sullivan, A.B., Rounds, S.A., Deas, M.L., Asbill, J.R., Wellman, R.E., Stewart, M.A., Johnston, M.W., and Sogutlugil, I.E., 2011, Modeling hydrodynamics, water temperature, and water quality in the Klamath River upstream of Keno Dam, Oregon, 2006-09: U.S. Geological Survey Scientific Investigations Report 2011-5105, 70 p. [Also available at https://pubs.usgs.gov/sir/2011/5105/.]

U.S. Environmental Protection Agency, 1993a, Method 353.2, revision 2.0-Determination of nitrate-nitrite nitrogen by automated colorimetry: Cincinnati, Ohio, U.S. Environmental Protection Agency, 14 p.

U.S. Environmental Protection Agency, 1993b, Method 350.1 - Determination of ammonia nitrogen by semi-automated colorimetry: Cincinnati, Ohio, U.S. Environmental Protection Agency, 12 p.

U.S. Environmental Protection Agency, 1993c, Method 351.2, revision 2.0-Determination of total Kjeldahl nitrogen by semi-automated colorimetry: Cincinnati, Ohio, U.S. Environmental Protection Agency, 15 p.

U.S. Environmental Protection Agency, 1993d, Method 365.1, revision 2.0-Determination phosphorus by semiautomated colorimetry: Cincinnati, Ohio, U.S. Environmental Protection Agency, 15 p.
U.S. Environmental Protection Agency, 2002, Guidelines establishing test procedures for the analysis of pollutantsAppendix B to part 136-Definition and procedure for the determination of the method detection limit-Revision 1.11): U.S. Code of Federal Regulations, Title 40, revised as of July 1, 2002, p. 635-638.

U.S. Environmental Protection Agency, 2007, Method 200.7Trace elements in water, solids, and biosolids by inductively coupled plasma-atomic emission spectrometry: Cincinnati, Ohio, U.S. Environmental Protection Agency, 68 p.

U.S. Geological Survey, 1999, The quality of our Nation's Waters-Nutrients and pesticides: U.S. Geological Survey Circular 1225, 82 p. [Also available at https://pubs.usgs.gov/circ/circ1225/pdf/index.html.]

U.S. Geological Survey, 2016, National Elevation Dataset: U.S. Geological Survey web page, accessed May 11, 2016, at https://www.usgs.gov/core-science-systems/nationalgeospatial-program/national-map.

U.S. Geological Survey, 2019, USGS water data for the Nation: U.S. Geological Survey National Water Information System database, accessed August 11, 2019, at https://doi.org/10.5066/F7P55KJN.

Wetzel, R.G., 2001, Limnology lake and river ecosystems 3d ed.: San Diego, Calif., Elsevier, 1006 p.

Wilde, F.D., ed., variously dated, Field measurements: U.S. Geological Survey Techniques of Water-Resources Investigations, book 9, chap. A6, accessed August 11, 2019, at https://pubs.water.usgs.gov/twri9A/.

Xu, H., Paerl, H.W., Qin, B., Zhu, G., and Gaoa, G., 2010, Nitrogen and phosphorus inputs control phytoplankton growth in eutrophic Lake Taihu, China: Limnology and Oceanography, v. 55 , no. 1, p. 420-432. [Also available at https://doi.org/10.4319/lo.2010.55.1.0420.] 
For more information about this publication, contact:

Director, USGS Upper Midwest Water Science Center 2280 Woodale Drive

Mounds View, MN 55112

763-783-3100

For additional information, visit:

https://www.usgs.gov/centers/umid-water

Publishing support provided by the

Rolla Publishing Service Center 



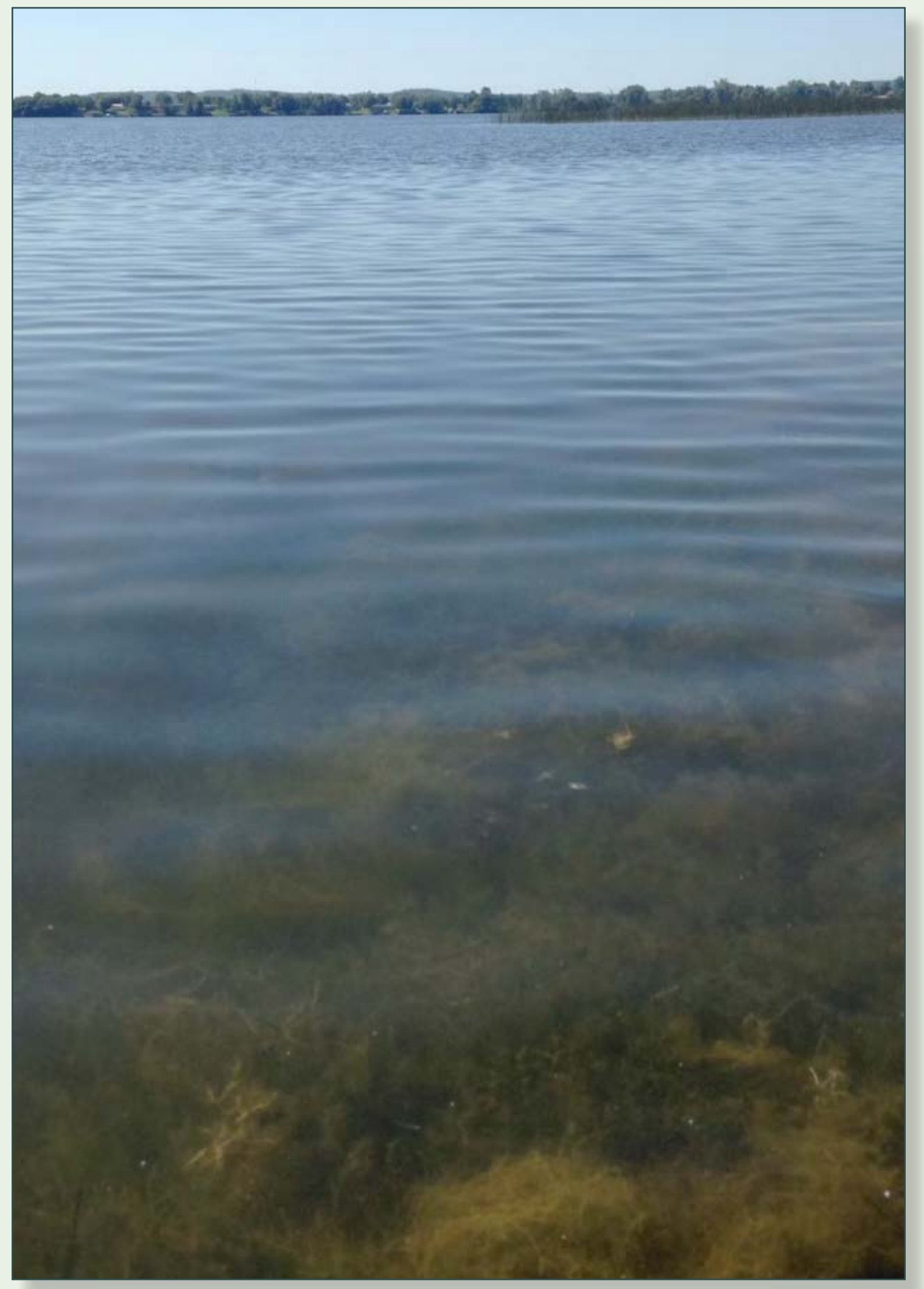

